\title{
Molybdenum disulfide/graphene oxide nanocomposites show favorable lung targeting and enhanced drug loading/tumor-killing efficacy with improved biocompatibility
}

\author{
Yun Liu ${ }^{1,2}$, Jian Peng ${ }^{3}$, Shunhao Wang ${ }^{1,4}$, Ming Xu ${ }^{1,4}$, Ming Gao ${ }^{1,4}$, Tian Xia ${ }^{5}$, Jian Weng ${ }^{3}$, An $\mathrm{Xu}^{2}$ and \\ Sijin Liu ${ }^{1,4}$
}

Selective targeting plus optimal biocompatibility is still a big challenge in nanomedicine. Although many nanomaterials including graphene oxide (GO) and molybdenum disulfide $\left(\mathrm{MoS}_{2}\right)$ have been tested for this purpose, these materials possess both favorable features and drawbacks, which hampers their further development. Herein, we prepared $\mathrm{MoS}_{2} / \mathrm{GO}$ nanocomposites that manifested excellent dispersity in aqueous solutions and revealed acceptable biocompatibility in vitro and in vivo. Importantly, $\mathrm{MoS}_{2} / \mathrm{GO}$ displayed a novel feature to selectively target the lung. In other words, $\mathrm{MoS}_{2} / \mathrm{GO}$ manifested a pronounced tendency of localization towards the lung comparable to GO, offering a 'guided missile' effect in targeting the lung. Furthermore, $\mathrm{MoS}_{2} / \mathrm{GO}$ composites possessed enhanced drug loading capacity together with reinforced tumor-killing efficacy against cancer cells that have the propensity to metastasize to the lung. Importantly, $\mathrm{MoS}_{2} / \mathrm{GO}$ composites remarkably repressed metastatic tumor growth of $\mathrm{B} 16$ murine melanoma cancer cells in lungs of mice. Mechanistically, $\mathrm{MoS}_{2} / \mathrm{GO}$ was demonstrated to reveal compromised reactions towards macrophages at the nano-bio interface relative to GO, which is accountable for the interaction and the uptake of nanosheets by macrophages associated with phagocytosis and macrophagic activation. Considered together, our findings established new $\mathrm{MoS}_{2} / \mathrm{GO}$ nanocomposites with multi-functionalities including selective lung targeting, favorable drug loading capacity, elevated tumor killing efficacy and improved biocompatibility. Our study opens an avenue for $\mathrm{MoS}_{2} / \mathrm{GO}$ nanocomposites in cancer nanotheranostics.

NPG Asia Materials (2018) 10, e458; doi:10.1038/am.2017.225; published online 5 January 2018

\section{INTRODUCTION}

Lung cancers and metastatic cancers to the lung from other primary sites account for the largest number of cancer deaths, considerable morbidity and huge healthcare burden. ${ }^{1-4}$ Thus, lung targeting is a long-searched solution to the therapeutics for lung cancers and metastatic cancers to the lung, while nanotechnology is undoubtedly integrating unprecedented science and technologies in facilitating this goal. ${ }^{5}$ Certainly, effective delivery of nanomaterials to the homing sites is of great importance in improving the accuracy and efficacy of nanomedicine. ${ }^{6}$ Nowadays, the main approaches to realize the goal of selective targeting are modifications on nanomaterials with specific antibodies (Abs), short peptide (for example, Arg-Gly-Asp (RGD) peptide), small molecules that possess targeting function (for example, folic acid (FA)) and magnetic targeting with the aid of exotic magnetic field. ${ }^{6-8}$ However, few nanomaterials could be used to target specific interest organs except liver dependent on the nanoparticles themselves thus far. Of note, unlike other nanomaterials, graphene oxide (GO) is able to localize in the lung through various exposure routes (for example, intravenous (i.v.) administration), ${ }^{9-12}$ being ascribed to the formation of GO-protein complexes that were readily caught by lung capillary vessels. ${ }^{13-15}$ GO's selective localization in the lung distinguishes it from other types of nanomaterials (mostly in liver and spleen), ${ }^{16,17}$ offering a 'guided missile' to target the lung. Nonetheless, many studies have shown that under certain conditions, GO is highly

\footnotetext{
${ }^{1}$ State Key Laboratory of Environmental Chemistry and Ecotoxicology, Research Center for Eco-Environmental Sciences, Chinese Academy of Sciences, Beijing, PR China; ${ }^{2}$ Key Laboratory of High Magnetic Field and Ion Beam Physical Biology, Hefei Institutes of Physical Science, Chinese Academy of Sciences; Anhui Province Key Laboratory of Environmental Toxicology and Pollution Control Technology, Hefei, Anhui, PR China; ${ }^{3}$ Research Center of Biomedical Engineering, Department of Biomaterials, College of Materials, Xiamen University, Xiamen, PR China; ${ }^{4}$ University of Chinese Academy of Sciences, Beijing, PR China and ${ }^{5}$ Division of NanoMedicine, Department of Medicine, University of California, Los Angeles, CA, USA

Correspondence: Professor A Xu, Key Laboratory of High Magnetic Field and Ion Beam Physical Biology, Hefei Institutes of Physical Science, Chinese Academy of Sciences; Anhui Province Key Laboratory of Environmental Toxicology and Pollution Control Technology, Hefei, Anhui 230031, PR China.

E-mail: anxu@ipp.ac.cn.

or Professor S Liu, State Key Laboratory of Environmental Chemistry and Ecotoxicology, Research Center for Eco-Environmental Sciences, Chinese Academy of Sciences, Beijing 100085, PR China.

E-mail: sjliu@rcees.ac.cn

Received 27 July 2017; revised 20 October 2017; accepted 5 November 2017
} 
toxic because of its reactive surface groups. ${ }^{18-21}$ For instance, our recent reports revealed an active interaction between $\mathrm{GO}$ and macrophages, inducing macrophagic pro-inflammatory responses, necrosis, cellular injuries and fibrosis., ${ }^{9,2}$ Therefore, improving GO's biocompatibility becomes a crucial prerequisite prior to expanding its bio-applications.

Molybdenum disulfide $\left(\mathrm{MoS}_{2}\right)$ nanomaterials are gaining mounting popularity with prospective application potentials in various fields due to their unique physicochemical properties, ${ }^{23-25}$ such as their utilization as an exceptional platform for diverse modifications and drug loading. ${ }^{26,27}$ Despite recent progresses, there are still considerable scientific and technical challenges for $\mathrm{MoS}_{2}$ nanomaterials in biomedical applications. For example, pristine $\mathrm{MoS}_{2}$ materials are poorly dispersible in aqueous solutions, ${ }^{28,29}$ which greatly restrains their bioapplications. Meanwhile, more work needs to be done to achieve diversified functionalization and selective targeting together with optimal biocompatibility. To this end, researches on bulk and simply functionalized $\mathrm{MoS}_{2}$ layers have been done extensively; however, the development for $\mathrm{MoS}_{2}$-centered biomedical applications is still in its infancy. Thus, more imperative strategies are needed to improve $\mathrm{MoS}_{2}$ functionalities for bio-applications.

Chemotherapeutic agents that harbor ample groups including hydroxyl and amino, such as doxorubicin (DOX), are inclined to form coordinate linkage with $\mathrm{Mo},{ }^{30,31}$ which renders $\mathrm{MoS}_{2}$ as a desirable vehicle for drug delivery. In the meantime, given the poor dispersity of bulk $\mathrm{MoS}_{2}$ and the inability to target specific tissue sites, more improvement therefore becomes very necessary for its biological applications, especially for targeted cancer nanotheranostics. ${ }^{28,32}$ In contrast, GO is highly soluble in aqueous solutions with a pronounced ability to target the lung. ${ }^{9}, 10,21$ Emerging evidence reports the applications of $\mathrm{MoS}_{2} / \mathrm{GO}$ nanocomposites in bioscience. ${ }^{33-35}$ For instance, $\mathrm{MoS}_{2} / \mathrm{GO}$ nanocomposites revealed a greater antibacterial activity, ${ }^{33}$ and enhanced selectivity and sensitivity in detecting glucose and hydrogen peroxide $\left(\mathrm{H}_{2} \mathrm{O}_{2}\right) .34,35$ Other than these, no further studies on other applications and biocompatibility have been conducted.

Thus, we brought about the idea of creating $\mathrm{MoS}_{2} / \mathrm{GO}$ nanocomposites, where they were constructed in order to combine the merits for both materials and shield the mutual weaknesses. To this end, the primary objective of the current study was to build up $\mathrm{MoS}_{2} / \mathrm{GO}$ nanocomposites that will show improved biocompatibility plus more desirable properties. Our results turned out that $\mathrm{MoS}_{2} / \mathrm{GO}$ nanocomposites manifested multi-functionalities including selective lung targeting, enhanced drug loading capacity, elevated tumor killing efficacy in vitro and in vivo, and improved biocompatibility as well. This study would open a new path that may lead to extensive use of $\mathrm{MoS}_{2} / \mathrm{GO}$ nanocomposites in cancer therapeutics.

\section{MATERIALS AND METHODS}

\section{Preparation of GO, $\mathrm{MoS}_{2} / \mathrm{GO}$ nanocomposites and $\mathrm{MoS}_{2}$ derivatives}

GO materials were prepared, as previously reported. ${ }^{36,37}$ Lysine (Lys) and FA were purchased from Sangon Biotech (Shanghai, China). All MoS 2 samples were prepared from an original batch of the bulk materials. To prepare $\mathrm{MoS}_{2} /$ GO nanocomposites and $\mathrm{MoS}_{2}$ derivatives, the bulk $\mathrm{MoS}_{2}$, purchased from Alfa Aesar (Tianjin, China), was dispersed in stock solutions of $0.5 \mathrm{mg} \mathrm{ml}^{-1} \mathrm{GO}$, Lys, and $\mathrm{FA}(\mathrm{pH}=7)$ in deionized water by sonication for $40 \mathrm{~h}$, respectively. As control, bulk $\mathrm{MoS}_{2}$ was sonicated alone in deionized water. These mixtures were left to stand for $48 \mathrm{~h}$ to allow unstable big aggregates to sediment. The dispersions were then centrifuged at 3000 r.p.m. for $20 \mathrm{~min}$. The supernatant was collected and further centrifuged at 12000 r.p.m. for $20 \mathrm{~min}$. The resulting precipitate was collected into new vials and dispersed in deionized water for further characterization and other experiments.

\section{Characterization of nanomaterials}

H-7500 transmission electron microscopy (TEM) (Hitachi Scientific Instruments, Tokyo, Japan) and atomic force microscopic 5500 in the contact mode (Agilent Technologies, Inc., Palo Alto, CA, USA) were used for characterizing the morphology, lateral size and thickness of synthesized nanomaterials. Dynamic light scattering and $\zeta$-potential of nanomaterials in deionized water and cell culture medium containing $10 \%$ fetal bovine serum (FBS) were determined using a Zetasizer (Malvern Nano series, Malvern, UK). Raman spectra were recorded using an InVia Raman microscope (Renishaw, London, UK) with a laser at the excitation wavelength of $532 \mathrm{~nm}$. Fourier transform infrared (FTIR) spectra of nanomaterials were recorded on a Nicolet 6700 FTIR spectrophotometer (Thermo Fisher Scientific Inc., Waltham, MA, USA), and obtained from the $\mathrm{KBr}$ pellet samples. Thermal gravimetric analysis was carried out on a SDT-Q600 instrument (TA, New Castle, PA, USA) at a heating rate of $10^{\circ} \mathrm{C} \mathrm{min}-1$ under nitrogen atmosphere. Scanning transmission electron microscopy-energy dispersive spectrometer (STEM-EDS) spectra for elemental mapping of $\mathrm{MoS}_{2} / \mathrm{GO}$ nanocomposites were performed on a JEM-2100 $\mathrm{F}$ electron microscope (JEOL, Tokyo, Japan). A DU-800 ultraviolet-visible (UVvis) spectrophotometer (Beckman, Fullerton, CA, USA) was used for UV-vis absorbance measurement.

\section{Animal experimentation and in vivo biodistribution of nanomaterials}

Male Balb/C mice (6-7 weeks old with body weight around $20 \mathrm{~g}$ ) were purchased from the Vital River Laboratories (Beijing, China). All animals were maintained and used in accordance with the Guidelines of the Animal Ethics Committee at the Research Center for Eco-Environmental Sciences, Chinese Academy of Sciences. For in vivo biodistribution and biocompatibility evaluation, mice were administrated with various nanomaterials via a single intratail vein injection in a total volume of $200 \mu \mathrm{l}$ at indicated concentrations. For the control group, mice received saline only. Next, $24 \mathrm{~h}$ after administration, mice were killed. The main organs (including the heart, liver, spleen, lung, kidney, brain, testis, muscle, bone marrow and peripheral blood) and blood serum were collected. Organs were weighed and digested overnight in nitric acid solution. Tissue Mo mass was quantified using an Agilent 7500 instrument (Agilent, Palo Alto, CA, USA).

\section{Fluorescent imaging of nanomaterials in mice}

For the fluorescent imaging of materials in vivo, an equal amount $(100 \mu \mathrm{g})$ of bulk $\mathrm{MoS}_{2}, \mathrm{MoS}_{2} / \mathrm{GO}, \mathrm{GO}$ and $\mathrm{FA}-\mathrm{MoS}_{2}$ were incubated with $100 \mu \mathrm{g}$ indocyanine green (ICG) for $24 \mathrm{~h}$ at room temperature. The ICG loading capacities were measured following the method for DOX loading, as described above. Afterwards, $16 \mu \mathrm{g}$ free ICG and ICG-labeled nanomaterials (all containing $16 \mu \mathrm{g} \mathrm{ICG)} \mathrm{were} \mathrm{administrated} \mathrm{into} \mathrm{mice} \mathrm{via} \mathrm{i.v.} \mathrm{administration.} \mathrm{After} 24 \mathrm{~h}$, mice were killed, lungs were collected and imaged to determine ICG fluorescence using a Xenogen IVIS spectrum (Caliper Life Sciences, Hopkinton, MA, USA). ICG fluorescence was recorded at $800 \mathrm{~nm}$ using an excitation wavelength of $745 \mathrm{~nm}$. The ICG fluorescence density was quantified by calculating the average radiant efficiency $\left(\left[\mathrm{p} / \mathrm{s} / \mathrm{cm}^{2} / \mathrm{sr}\right] /\left[\mu \mathrm{W} / \mathrm{cm}^{2}\right]\right)$.

\section{Drug loading capacity}

The drug loading capacities of different nanomaterials were detected using a UV-vis spectrophotometer (Beckman, Fullerton, CA, USA), as reported by Yin et al. $^{32} \mathrm{In}$ brief, $0.1 \mathrm{mg} \mathrm{ml}^{-1} \mathrm{MoS}_{2} / \mathrm{GO}, 0.058 \mathrm{mg} \mathrm{ml}^{-1} \mathrm{GO}, 0.042 \mathrm{mg} \mathrm{ml}^{-1}$ bulk $\mathrm{MoS}_{2}$, Lys- $\mathrm{MoS}_{2}$ and FA-MoS nanomaterials were mixed with free DOX at different concentrations $\left(0.05\right.$ and $\left.0.1 \mathrm{mg} \mathrm{ml}^{-1}\right)$ in phosphate-buffered saline (PBS) containing 2\% FBS (to avoid $\mathrm{MoS}_{2}$ and GO aggregation with salt ions). The mixtures were stirred for $24 \mathrm{~h}$ at room temperature. Unbounded DOX was washed away by centrifugation and repeated washing with PBS. The resulting precipitates were re-dispersed and stored at $4{ }^{\circ} \mathrm{C}$. All the supernatants obtained from each wash were collected and used to determine the amount of excess free DOX at the absorbance peak of $480 \mathrm{~nm}$. DOX loading capacity was 
calculated using the following equation:

$$
\text { Loading efficiency }(\%)=\frac{M V\left(C_{0}-C_{\mathrm{e}}\right)}{m} \times 100 \%
$$

In the above equation, $M\left(\mathrm{~g} \mathrm{~mol}^{-1}\right)$ is the molar mass of DOX; $V(\mathrm{l})$ is the volume of supernatant; $C_{0}\left(\mathrm{moll}^{-1}\right)$ and $C_{\mathrm{e}}\left(\mathrm{moll}^{-1}\right)$ are the initial and equilibrium concentrations of DOX in PBS buffer, respectively; $m(\mathrm{~g})$ is the mass of nanomaterials.

\section{Cell culture}

Murine macrophage cell line J774A.1, mouse Lewis lung carcinoma cell line, mouse melanoma cell line B16, original mouse breast cancer cell line 4T1 and human breast cancer cell line MDA-MB-231 were obtained from the Shanghai Cell Bank of Type Culture Collection of China. The 4T1 subline with strong lung metastasis was created by our own laboratory. ${ }^{38}$ Cells were cultured continuously at $37^{\circ} \mathrm{C}$ and $5 \% \mathrm{CO}_{2}$ in Dulbecco's modified Eagle medium or RPMI- 1640 medium (Gibco BRL Life Technologies Inc., Waltham, MA, USA) with 10\% FBS and 100 units $\mathrm{ml}^{-1}$ penicillin/streptomycin (Invitrogen, Waltham, MA, USA).
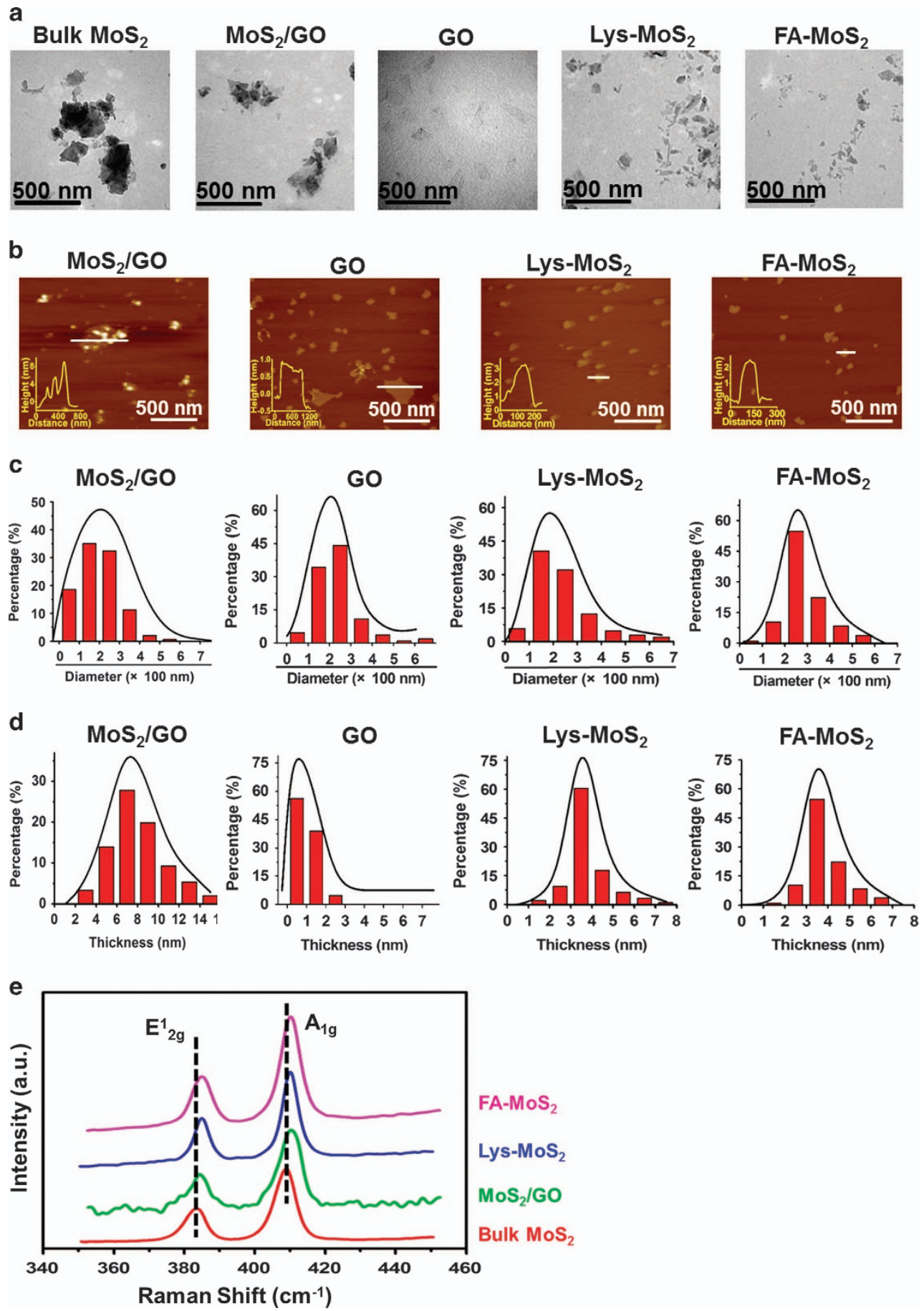

Figure 1 Physicochemical characterization of nanomaterials. (a) Representative TEM images of bulk MoS 2 , MoS $/$ GO nanocomposite, GO and Lys-MoS 2 and

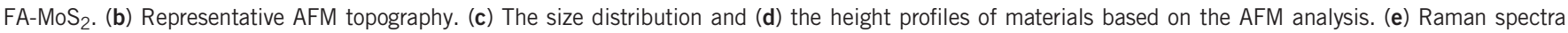
of various materials. TEM, transmission electron microscopy; $\mathrm{MoS}_{2}$, molybdenum disulfide; GO, graphene oxide; AFM, atomic force microscopy. 


\section{In vitro tumor-killing capability assay}

First, an equal amount $(100 \mu \mathrm{g})$ of diverse nanomaterials were incubated with $50 \mu \mathrm{g}$ DOX for $24 \mathrm{~h}$ at room temperature. DOX-loaded nanomaterials were then purified with repeated centrifugation and PBS washing. Thereafter, $\mathrm{MoS}_{2} /$ GO@DOX, GO@DOX, Lys-MoS $\mathrm{M}_{2} @ \mathrm{DOX}$ and FA-MoS $\mathrm{S}_{2} @ \mathrm{DOX}$ complexes were exposed to different types of tumor cells. After $24 \mathrm{~h}$, cell morphologies were imaged on an Axiovert 40 CFL microscope (ZEISS, Oberkochen, Germany), and cytotoxicity was determined using a cell counting kit (CCK)-8 (Solarbio, Beijing, China) following the manufacturer's instructions.

\section{In vivo anti-tumor evaluation in mice}

To establish the mouse model, male C57BL/6 mice (6-7 weeks old) were randomly divided into six groups $(n=6-7)$, and were then injected with B16 cells $\left(2 \times 10^{5}\right.$ cells per mouse) via i.v. administration on day 1 . Mice thereafter received treatments with DOX ( $1.5 \mathrm{mg} \mathrm{kg}^{-1}$ body weight), or DOX-loaded nanomaterials (with an equal amount of DOX) through i.v. injection every 3 days beginning on day 3 . Mice were killed for examination of metastatic tumors on day 18. Blank control mice received saline only. Body weight of all mice was monitored every other day.

\section{Blood biochemistry assay}

The activities of aspartate aminotransferase in mouse sera were assayed using a kit from Nanjing Jiancheng Bioengineering Institute, Nanjing, China. The concentrations of interleukin- 6 and tumor necrosis factor (TNF)- $\alpha$, either in mouse sera or in cell culture media, were quantitatively assessed using kits from R\&D Systems Inc., Minneapolis, MN, USA. The concentrations of monocyte chemotactic protein (MCP)-1, MCP-3, and macrophage inflammatory protein$1 \alpha$ in cell culture media, were quantitatively assessed using kits from Wuhan USCN Business Co., Ltd, Wuhan, China and Neobioscience Technology Company, Beijing, China.

\section{Histological examination, Masson's trichrome and immunehistochemical staining}

For the biocompatibility assay, $0.84 \mathrm{mg} \mathrm{kg}^{-1}$ body weight bulk $\mathrm{MoS}_{2}$, Lys$\mathrm{MoS}_{2}$ and FA-MoS, $1.16 \mathrm{mg} \mathrm{kg}^{-1}$ body weight GO and $2 \mathrm{mg} \mathrm{kg}^{-1}$ body weight $\mathrm{MoS}_{2} / \mathrm{GO}$ were administrated in mice. When mice were killed, organs were immediately collected and fixed with $10 \%$ formalin in PBS. Tissues were embedded in a paraffin block and then sliced into thick sections $(5 \mu \mathrm{m})$ onto glass slides. Following the standard protocols, hematoxylin and eosin, Masson's trichrome and immunehistochemical staining were performed. An $\mathrm{Ab}$ against CD68 (Santa Cruz Biotechnology, Santa Cruz, CA, USA) was used to recognize macrophages in immunohistochemistry. Slides were observed and imaged with an Axio Scope Al optical microscope (CarlZeiss, Inc., Oberkochen, Germany).

\section{Cell number counting}

Cells were first seeded at a density of $7 \times 10^{4}$ cells per well in 24 -well plates and were then cultured for $24 \mathrm{~h}$. Cells were afterwards treated with different concentrations of nanomaterials for another $24 \mathrm{~h}$. After treatment, cells were then harvested for counting the number of live cells using a NovoCyte 1040 flow cytometer (ACEA BIO, Hangzhou, China).

\section{Reactive oxygen species detection}

Cells were first seeded in 96-well plates overnight. Cells were then treated with different materials for 1, 6 and $24 \mathrm{~h}$. After treatment, medium was removed and cells were washed with PBS. After incubation with a $10 \mu \mathrm{M}$ 2',7'-dichlorofluorescin diacetate (DCF-DA) probe molecules for $30 \mathrm{~min}$ at $37^{\circ} \mathrm{C}$, cells were washed with PBS for three times. DCF-DA fluorescence was recorded at $525 \mathrm{~nm}$ using an excitation wavelength at $488 \mathrm{~nm}$ on a Vakioskan flash plate reader (Thermo Scientific, Waltham, MA, USA). For the dynamic reactive oxygen species (ROS) detection within a short time period, DCF-DA probes were first added into cells and incubated for $30 \mathrm{~min}$ at $37^{\circ} \mathrm{C}$, and cells were then washed with PBS for three times. DCF-DA fluorescence was recorded immediately after cells were treated with nanomaterials within $1 \mathrm{~h}$ at an interval of every $5 \mathrm{~min}$.

\section{Cellular localization of nanomaterials through TEM}

Cells were seeded in $6 \mathrm{~cm}$ plates at a density of $2 \times 10^{6}$ per plate and were cultured for $24 \mathrm{~h}$. Cells were then exposed to materials for $24 \mathrm{~h}$, followed by cell collection. The harvested cells were fixed with $2.5 \%$ glutaraldehyde solution and embedded with epoxy resin. The TEM samples were prepared, as previously reported. ${ }^{39}$ Areas containing cells were block mounted and cut into ultrathin sections $(70 \mathrm{~nm})$. The ultrathin cell specimens were placed on the grids, stained with $1 \%$ lead citrate and $0.5 \%$ uranyl acetate and finally examined. Subcellular localization of nanomaterials was detected using a high-resolution JEOL JEM 2010F transmission electron microscope (Hitachi Scientific Instruments, Tokyo, Japan).

\section{Quantitative reverse transcription-polymerase chain reaction assay} of gene expression

Quantitative reverse transcription-polymerase chain reaction (qRT-PCR) analysis was performed to characterize the expression levels of interest genes. Briefly, after cellular treatment, total RNAs were isolated from cells using Trizol (Life Technologies, Waltham, MA, USA). qRT-PCR analysis of the mRNA levels for various chemokines was performed using SYBR Green qPCR mix (Promega Inc., Madison, WI, USA) on an Mx3005P qRT-PCR instrument (Bio-Rad, Hercules, CA, USA). The primer sequences for PCR reactions are listed in Supplementary Figure S1. GAPDH was used as the internal control for normalization.

\section{Statistical analysis}

All data were represented as the mean \pm standard deviation (s.d.). Statistical analysis was performed using independent $t$-test or one-way ANOVA test. $P$ value less than $0.05(P<0.05)$ was considered statistically significant.

\section{RESULTS AND DISCUSSION}

\section{Synthesis and characterization of $\mathrm{MoS}_{2} / \mathrm{GO}$ nanocomposites}

To prepare $\mathrm{MoS}_{2}$ and GO hybrid materials, GO monolayer sheets were doped on $\mathrm{MoS}_{2}$ layers to form few-layer nanocomposites. The thermal gravimetric analysis unveiled that the component ratio for $\mathrm{MoS}_{2}$ and GO was 42 vs $58 \%$ within the $\mathrm{MoS}_{2} / \mathrm{GO}$ composites (Supplementary Figure S2). Pristine $\mathrm{MoS}_{2}$ materials are poorly dispersible and tend to dramatically aggregate in water and physiological solutions, ${ }^{26,28,29}$ which prevents the biomedical applications. Lys and FA are two main types of small molecules with excellent biocompatibility and are often used to modify nanomaterials. ${ }^{40,41}$ To this end, apart from bulk $\mathrm{MoS}_{2}$, simply functionalized $\mathrm{MoS}_{2}$ materials including Lys- and FA-modified $\mathrm{MoS}_{2}$ were also synthesized using the same batch of bulk $\mathrm{MoS}_{2}$ materials as additional controls alongside $\mathrm{MoS}_{2}$ /GO nanocomposites. Meanwhile, the same batch of GO sheets used for $\mathrm{MoS}_{2}$ hybrid was also used here for comparison. Thereafter, our synthesized materials were extensively characterized. Figure 1a shows the morphologies and structures of all materials, as characterized by TEM. Consistent with previous observations, ${ }^{28,42}$ bulk $\mathrm{MoS}_{2}$ materials were not well dispersed in aquatic solutions and formed agglomerates, as evidenced by the TEM images (Figure 1a). By contrast, GO exhibited a single-layer sheet-like structure, while $\mathrm{MoS}_{2} / \mathrm{GO}$ composites, Lys-MoS 2 and FA-MoS 2 all appeared in a few-layer sheet-like structure without agglomeration (Figure 1a). Atomic force microscopic analysis further confirmed the structures and morphologies of GO, $\mathrm{MoS}_{2} / \mathrm{GO}, \mathrm{Lys}-\mathrm{MoS}_{2}$ and $\mathrm{FA}-\mathrm{MoS}_{2}$ (Figure 1b). The statistical analysis of atomic force microscopic results showed that more than $90 \%$ sheets of GO, $\mathrm{MoS}_{2} / \mathrm{GO}, \mathrm{Lys}-\mathrm{MoS}_{2}$ and FA- $\mathrm{MoS}_{2}$ had a similar lateral size ranging from 50 to $350 \mathrm{~nm}$ (Figure 1c). Atomic force microscopic data demonstrated that the average thickness of GO sheets was approximately $1.0 \mathrm{~nm}$ (Figure 1d), indicative of single-layer graphene sheets. ${ }^{43}$ Lys- $\mathrm{MoS}_{2}$ and FA-MoS also revealed a similar thickness ranging from 2.5 to $5.5 \mathrm{~nm}$, whereas 
the formation of composites significantly increased the thickness to 5$11 \mathrm{~nm}$ for $\mathrm{MoS}_{2} / \mathrm{GO}$ (Figure 1d).

Afterwards, Raman and FTIR spectroscopy were employed to verify the structure and functional groups on the materials. As shown in Figure 1e, Raman spectra indicated that bulk $\mathrm{MoS}_{2}, \mathrm{MoS}_{2} / \mathrm{GO}$, Lys$\mathrm{MoS}_{2}$ and FA-MoS 2 revealed two typical peaks: $\mathrm{E}_{2 \mathrm{~g}}^{1}$ and $\mathrm{A}_{1 \mathrm{~g}}$, suggestive of the vibrations (in-plane) of $2 \mathrm{~S}$ atoms with the Mo atom, and the vibrations (out of plane) of $\mathrm{S}$ atoms in opposite directions, respectively. ${ }^{44,45}$ Of note, after functionalization, a blue shift for peak $\mathrm{E}_{2 \mathrm{~g}}^{1}$ and $\mathrm{A}_{1 \mathrm{~g}}$ was found in the spectra of $\mathrm{MoS}_{2} / \mathrm{GO}, \mathrm{Lys}_{-} \mathrm{MoS}_{2}$ and FA$\mathrm{MoS}_{2}$, demonstrating the successful synthesis of these materials (Figure 1e). FTIR spectra verified the successful modification on $\mathrm{MoS}_{2}$ by GO, Lys and FA, as $\mathrm{MoS}_{2} / \mathrm{GO}$, Lys- $\mathrm{MoS}_{2}$ and FA-MoS displayed similar typical stretching peaks to their original modification materials, respectively (Supplementary Figure S3). Additionally, STEM-EDS was performed for the purpose of elemental mapping on $\mathrm{MoS}_{2}$ /GO materials. As shown in Supplementary Figure S4, the distribution of $\mathrm{Mo}, \mathrm{S}, \mathrm{C}$ and $\mathrm{O}$ elements displayed a constant overlay in STEM imaging, confirming the synchronized integration of $\mathrm{MoS}_{2}$ and GO into the composites.

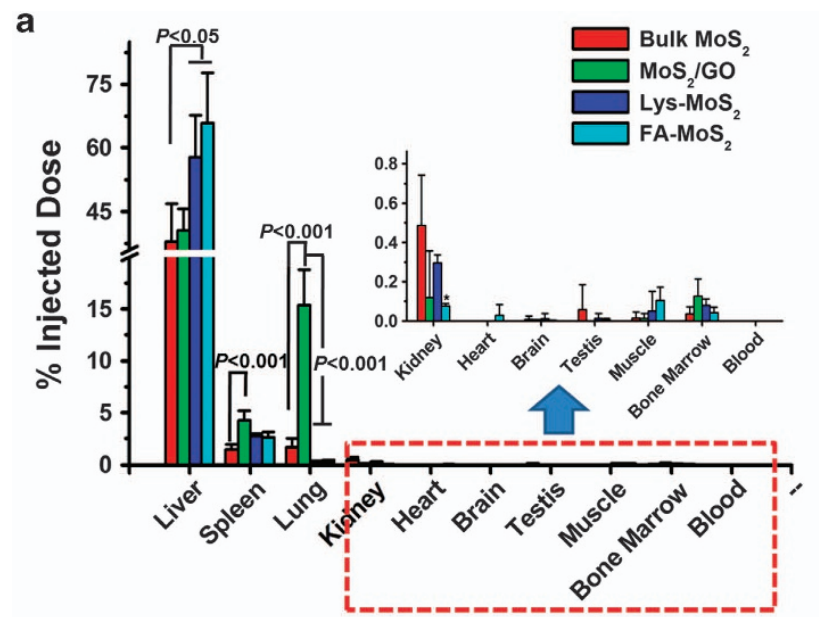

b

\begin{tabular}{|c|c|c|c|c|}
\hline Tissue & Bulk $\mathrm{MoS}_{2}$ & $\mathrm{MoS}_{2} / \mathrm{GO}$ & Lys-Mos 2 & FA-MoS 2 \\
\hline Liver & $1.255 \pm 0.260$ & $1.015 \pm 0.140$ & $1.363 \pm 0.229$ & $1.498 \pm 0.123$ \\
\hline Spleen & $0.437 \pm 0.119$ & $1.026 \pm 0.220^{*}$ & $0.752 \pm 0.055$ & $0.580 \pm 0.097$ \\
\hline Lung & $0.299 \pm 0.133$ & $2.005 \pm 0.435 \#$ & $0.044 \pm 0.020^{*}$ & $0.036 \pm 0.033$ * \\
\hline Kidney & $0.058 \pm 0.043$ & $0.002 \pm 0.004$ & $0.005 \pm 0.012$ & - \\
\hline Heart & $0.027 \pm 0.061$ & - & - & - \\
\hline Brain & $0.001 \pm 0.001$ & - & $0.002 \pm 0.002$ & - \\
\hline Testis & $0.001 \pm 0.001$ & - & $0.007 \pm 0.006$ & - \\
\hline Muscle & $0.004 \pm 0.005$ & - & $0.009 \pm 0.004$ & $0.002 \pm 0.002$ \\
\hline $\begin{array}{c}\text { Bone } \\
\text { Marrow }\end{array}$ & $1.914 \pm 0.528$ & $2.921 \pm 1.056$ & $2.192 \pm 0.726$ & $1.747 \pm 0.584$ \\
\hline Blood & - & $0.013 \pm 0.015$ & - & - \\
\hline
\end{tabular}

Figure 2 In vivo biodistribution of various materials in mice. The Mo contents were examined in mice $24 \mathrm{~h}$ post i.v. injection. The results from ICP-MS determination were shown as (a) \% of injected dose and (b) $\mu \mathrm{g} \mathrm{g}^{-1}$. There were six mice per group $(n=6)$. Asterisk $(*)$ indicates $P<0.05$ and pound sign (\#) denotes $P<0.001$, compared to bulk $\mathrm{MoS}_{2}$-treated group. Dash (-) indicates not detectable. $\mathrm{MoS}_{2}$, molybdenum disulfide.
Moreover, the dispersity of these materials was thoroughly investigated. As shown in Supplementary Figure S5, bulk $\mathrm{MoS}_{2}$ did not disperse in water and culture medium plus 10\% FBS with the hydrodynamic size from 720 to $850 \mathrm{~nm}$. In contrast, GO was well dispersed in water and culture medium with the hydrodynamic size from 200 to $270 \mathrm{~nm}$ (Supplementary Figure S5), consistent with previous reports. ${ }^{9,10,46}$ Owing to the abundant oxygen-containing functional groups on its surface, GO exhibits excellent dispersity in water, which is a crucial prerequisite for its biomedical applications. ${ }^{21}$ As a result, $\mathrm{MoS}_{2} / \mathrm{GO}$ manifested great dispersity in water and cell culture medium with $10 \%$ FBS, similar to $\mathrm{Lys}-\mathrm{MoS}_{2}$ and FA-MoS 2 , and the hydrodynamic size was considerably reduced to $140-160 \mathrm{~nm}$ in water and $180-270 \mathrm{~nm}$ in culture medium, respectively (Supplementary Figure S5, $P<0.05$ ). It is worthwhile noting that the hydrodynamic size became larger in culture medium with FBS than that in water for all materials (Supplementary Figure S5, $P<0.001$ ), due to the formation of protein corona on their surface. ${ }^{10}$ Further, the polydispersity index data overall supported the finding of enhanced dispersity for $\mathrm{MoS}_{2} / \mathrm{GO}$, Lys- $\mathrm{MoS}_{2}$ and FA$\mathrm{MoS}_{2}$ relative to bulk $\mathrm{MoS}_{2}$ (Supplementary Figure S5, $P<0.05$ ). Additionally, the $\zeta$-potential data showed that all materials were negatively charged in water and cell culture medium with FBS (Supplementary Figure S5). Together, these results demonstrated that $\mathrm{MoS}_{2} / \mathrm{GO}$ nanocomposites were successfully prepared with improved dispersity, and, for the purpose of comparison, Lys- $\mathrm{MoS}_{2}, \mathrm{FA}-\mathrm{MoS}_{2}$ and GO materials were also well prepared.

\section{Preferential lung accumulation of $\mathrm{MoS}_{2}$ /GO nanocomposites}

To improve the therapeutic efficacy, the accuracy of selective targeting is of great importance. ${ }^{5}$ To achieve enhanced tissue targeting, tremendous attempts have been made through versatile strategies, including $3 S^{\prime}$ optimization (that is, size, shape and surface), surface coating with chemical and/or biological molecules and targeting ligands. ${ }^{47,48}$ Nonetheless, emerging evidence also suggests that the nanomaterials themselves could be refined for specific tissue accumulation and thus targeting through either a passive or active mechanism. ${ }^{49,50}$ GO materials were uncovered to preferentially localize in the lung upon in vivo administration, ${ }^{9-12}$ pointing out the rationale of using GO for lung targeting. To this end, we synthesized the $\mathrm{MoS}_{2} / \mathrm{GO}$ nanocomposites for the purpose of lung targeting. First, the lung targeting effect was determined by assessing the biodistribution of these materials in mice after i.v. administration. The relative distribution was described as percentage (\%) of injected dose, denoting the proportion of materials in each whole organ of the total injected mass. Similar to the distribution profile of most nanomaterials, ${ }^{17,51}$ these materials predominantly accumulated in liver, with much less amount in spleen, lung and kidney and neglectable amount in other places, such as heart, brain, testis, muscle, bone marrow and peripheral blood (Figure 2a, $\mathrm{P}<0.001$ ). Most distinctively, $\mathrm{MoS}_{2} / \mathrm{GO}$ composites displayed differential localization from bulk $\mathrm{MoS}_{2}$, Lys- $\mathrm{MoS}_{2}$ and FA-MoS 2 , as $\mathrm{MoS}_{2} / \mathrm{GO}$ composites exhibited preferential accumulation in the lung with nine times greater than bulk $\mathrm{MoS}_{2}$ and 50 times greater than Lys-MoS 2 and FA-MoS (Figure $2 \mathrm{a}, \mathrm{P}<0.001$ ). This finding was consistent with the inclined deposition of GO in the lung upon in vivo administration. ${ }^{9-11}$ To further substantiate these results, mass concentration for each organ was calculated. As shown in Figure 2b, mass concentration profiles for organs showed a similar pattern to that of the total amount in according organs.

To corroborate the preferential tendency of $\mathrm{MoS}_{2} / \mathrm{GO}$ composites to deposit in the lung, in vivo localization of these materials was 


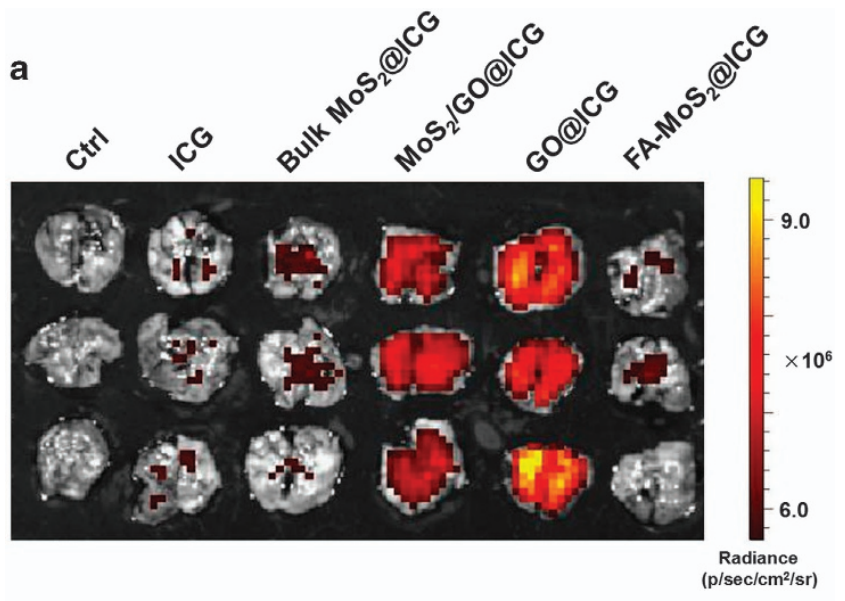

b

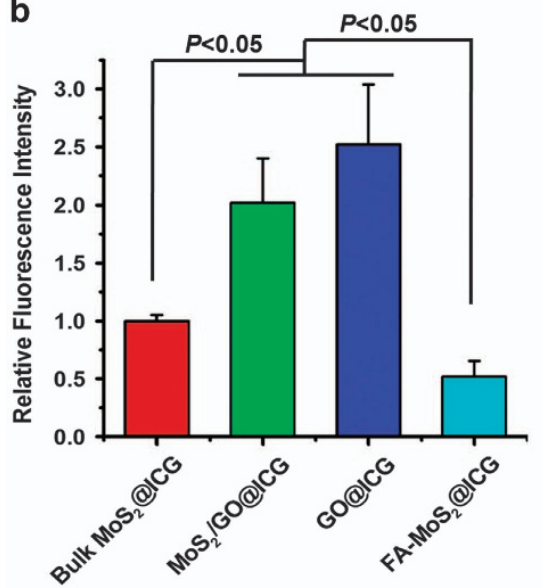

Figure 3 In vivo imaging and lung accumulation analysis. (a) ICG fluorescent images of lungs from mice $24 \mathrm{~h}$ post-injection of free ICG and ICG-loaded nanomaterials. (b) Quantification of relative ICG fluorescence in lungs $(n=3)$. ICG, indocyanine green.

visualized through labeling with a Food and Drug Administrationapproved fluorescence dye, ICG. Here, bulk $\mathrm{MoS}_{2}, \mathrm{GO}, \mathrm{MoS}_{2} / \mathrm{GO}$ composites and FA-MoS $\mathrm{S}_{2}$ with the same amount of ICG conjugation were subjected to in vivo imaging through the ICG fluorescence. As reported previously, ${ }^{52,53}$ the mechanisms for loading ICG onto $\mathrm{MoS}_{2} /$ GO nanocomposites mainly reside in the $\pi-\pi$ stacking interaction and hydrophobic effect. As shown in Figure 3a, a much higher level of fluorescence was observed in lungs from mice administrated with GO@ICG and $\mathrm{MoS}_{2} / \mathrm{GO} @ I C G$ than that in lungs from mice administrated with bulk $\mathrm{MoS}_{2} @ \mathrm{ICG}$ and FA-MoS $@$ ICG. Quantitative data further verified the enrichment of ICG fluorescence in lungs of mice treated with GO@ICG and $\mathrm{MoS}_{2} / \mathrm{GO} @ \mathrm{ICG}$, compared to bulk $\mathrm{MoS}_{2} @ \mathrm{ICG}-$ and FA-MoS ${ }_{2} @ I C G-t r e a t e d$ mice (Figure 3b, $\mathrm{P}<0.05$ ). A comparable level of fluorescence intensity was found between GO@ICG and $\mathrm{MoS}_{2}$ /GO@ICG in lungs, suggesting a great contribution of GO in guiding lung localization. Unlike most of the other nanomaterials, GO tended to localize in the lung via various exposure routes. ${ }^{9-12}$ To be specific, GO was prone to form complex with diverse proteins once in circulation and body fluid, and would mostly likely be trapped in the arteries and capillaries in the lung, which functioned as the first vascular bed for GO sheet localization. ${ }^{10,13,54}$ Meanwhile, the microenvironment of pulmonary vasculature, such as endothelial caveolae ${ }^{55}$ and distinct membrane proteins on the luminal surface of lung vascular endothelial cells, ${ }^{56}$ may also be accountable for targeting of GO sheets. Through building up the $\mathrm{MoS}_{2} / \mathrm{GO}$ nanocomposites, GO was made the best to guide $\mathrm{MoS}_{2}$ to accumulate in the lung, adding a favorable property to nanocomposites for selective lung targeting. Thus, our findings may pinpoint the potential application of $\mathrm{MoS}_{2} / \mathrm{GO}$ nanocomposites in selective lung targeting in treating lungassociated disorders. We here focused on the study of $\mathrm{MoS}_{2} / \mathrm{GO}$ nanocomposites for targeting cancer cells prone to the lung, and we did not look into the interaction between $\mathrm{MoS}_{2} / \mathrm{GO}$ nanocomposites and pulmonary membrane proteins. Nevertheless, it is an important aspect to be extensively investigated in the future. In fact, in a recent paper published by our group, ${ }^{46}$ we shed light on the interaction between GO nanosheets and membrane proteins on A549 lung epithelial cells. In this report, various pathways related to the functions of plasma membrane (for example, focal adhesion, tight junction and endocytosis) were found to be affected in cells responding to low-dose exposure of GO. For the next step, we will invest more efforts to elaborate the interaction between $2 \mathrm{D}$ nanomaterials (that is, GO and $\mathrm{MoS}_{2}$ ) and cell membrane proteins.

Enhanced capacity of $\mathrm{MoS}_{2} / \mathrm{GO}$ nanocomposites to load DOX and to kill tumor cells in vitro and in vivo

Thereafter, $\mathrm{MoS}_{2}$ /GO's functionality and biocompatibility were compared to bulk $\mathrm{MoS}_{2}$, Lys- $\mathrm{MoS}_{2}, \mathrm{FA}-\mathrm{MoS}_{2}$ and GO at the same mass concentrations proportional to the component ratio (namely, $\mathrm{MoS}_{2}$ : GO $=42 \%: 58 \%$ ). Since both $\mathrm{MoS}_{2}$ and GO are promising materials for biomedical applications, for example, drug loading vehicles in cancer nanotheranostics, we thus assessed the capacity of these materials to load DOX, a mainstream chemotherapeutic agent in treating diverse cancers. As shown in Figure 4a, $\mathrm{MoS}_{2} / \mathrm{GO}$ nanocomposites harbored enhanced capacity to load DOX (40\%), 10-fold greater than bulk $\mathrm{MoS}_{2}$ (4\%), fourfold greater than $\mathrm{Lys}_{-} \mathrm{MoS}_{2}(10 \%)$ and about twofold greater than FA- $\mathrm{MoS}_{2}(21 \%)$ when incubating in the solution with DOX at the $0.05 \mathrm{mg} \mathrm{ml}^{-1}(P<0.05) . \mathrm{MoS}_{2} / \mathrm{GO}$ nanocomposites also revealed greater DOX loading capacity with $32 \%$ increase, relative to GO (Figure $4 \mathrm{a}, \mathrm{P}<0.05$ ). Similar findings were obtained for $\mathrm{MoS}_{2} / \mathrm{GO}$ nanocomposites when incubating in the solution with DOX at the $0.1 \mathrm{mg} \mathrm{ml}^{-1}$ in comparison to bulk $\mathrm{MoS}_{2}$, Lys- $\mathrm{MoS}_{2}$ and FA-MoS 2 and GO (Figure 4a, P<0.05). UVvis spectra and FTIR analyses were further carried out to affirm the loading of DOX onto $\mathrm{MoS}_{2} / \mathrm{GO}$ nanocomposites. As shown in Supplementary Figure S6, the UV-vis spectra were recorded in the wavelength ranging from 200 to $800 \mathrm{~nm}$. DOX loaded onto $\mathrm{MoS}_{2} / \mathrm{GO}$ nanocomposites was evidenced by a pronounced absorption peak at $\sim 480 \mathrm{~nm}^{32}$ As presented by the FTIR data in Supplementary Figure S7, compared with $\mathrm{MoS}_{2} / \mathrm{GO}$ alone, additional bands appeared on the FTIR spectrum for $\mathrm{MoS}_{2} / \mathrm{GO} @ D O X$. For instance, the band at $1605 \mathrm{~cm}^{-1}$ was obtained owing to the vibration of the benzene ring frame of DOX. And the band at $1720 \mathrm{~cm}^{-1}$ was attributed to the carbonyl peak from DOX. Moreover, the peak at $880 \mathrm{~cm}^{-1}$ referred to the primary amine wag vibration of DOX. ${ }^{32}$ These results collectively suggested that $\mathrm{MoS}_{2} / \mathrm{GO}$ nanocomposites possessed greatly enforced drug loading capacity than individual $\mathrm{MoS}_{2}$ and GO, suggesting enhanced tumor-killing capability for $\mathrm{MoS}_{2} / \mathrm{GO}$ composites. It is worth noting that our $\mathrm{MoS}_{2} / \mathrm{GO}$ nanocomposites even showed greater DOX loading capacity when comparing with other mainstream nanomaterials reported previously, including PEGylated $\mathrm{MoS}_{2}$ nanosheets, ${ }^{28}$ PEGylated GO nanosheets, ${ }^{57}$ poly(propylene imine)dendrimer-grafted gold nanoparticles ${ }^{58}$ and FA-conjugated polydopamine-modified mesoporous silica nanoparticles. ${ }^{59}$ With respect to the mechanisms underlying DOX-loading onto $\mathrm{MoS}_{2} / \mathrm{GO}$ nanocomposites, at least three interactions are involved. First, GO nanosheets 
a

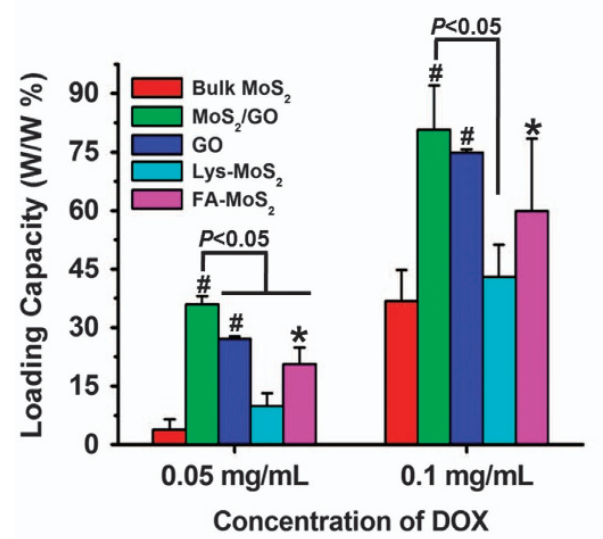

b

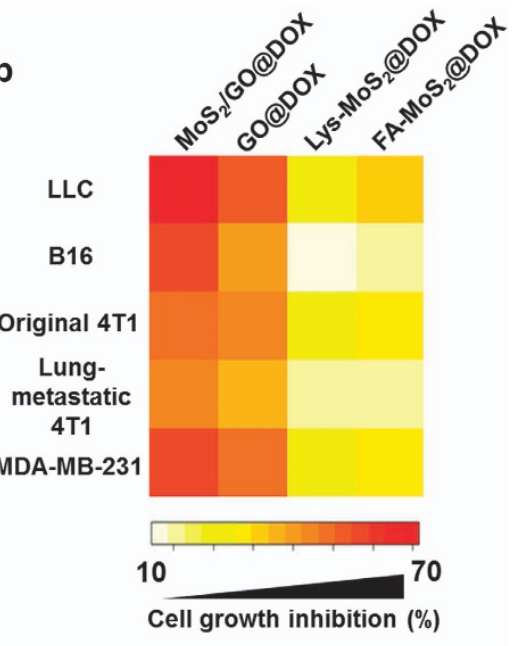

C Ctrl

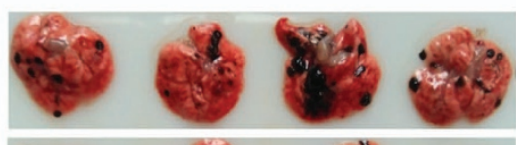

\section{DOX}

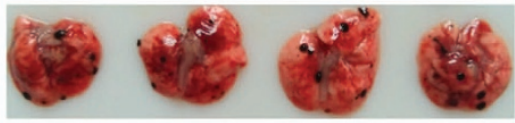

$\mathrm{MoS}_{2} / \mathrm{GO}$

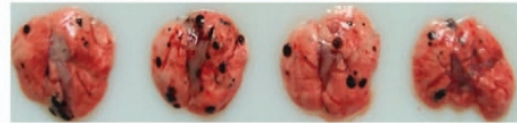

Lys-MoS ${ }_{2} @ D O X$

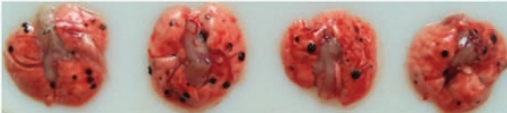

GO@DOX
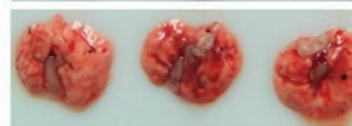

$\mathrm{MoS}_{2} / \mathrm{GO} @ D O X$

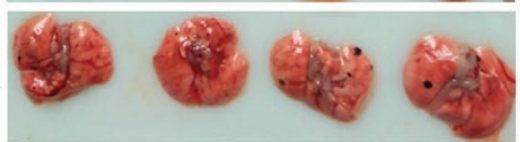

Figure 4 DOX loading capacity and tumor killing efficacy of different materials. (a) DOX loading capacity of nanomaterials $(n=4)$. (b) In vitro tumor killing efficacy of DOX-loaded materials at the same mass concentrations $(n=5)$. The concentrations of materials were tailored for each type of cells as follows: $2 \mu \mathrm{g} \mathrm{ml}^{-1}$ for LLC cells, $6 \mu \mathrm{g} \mathrm{ml}-1$ for B16 cells, $30 \mu \mathrm{g} \mathrm{ml}-1$ for $4 \mathrm{~T} 1$ cells and $15 \mu \mathrm{g} \mathrm{ml}-1$ for MDA-MB-231 cells. (c) Representative images of metastatic tumor nodules in the lungs from treated and untreated mice with implantation of B16 murine melanoma cancer cells. DOX, doxorubicin; LLC, Lewis lung carcinoma.

consist of $\mathrm{sp}^{2}$-bonded carbon on the aromatic network and various functional groups (that is, hydroxyl, carboxyl and epoxide) on the surfaces of each sheet. ${ }^{60}$ Thus, the $\pi-\pi$ stacking interaction can be formed between the large $\pi$ conjugated structure of GO and the quinone structure of DOX. Second, a hydrophobic effect contributed to the interaction between GO and DOX, and between $\mathrm{MoS}_{2}$ and DOX as well. And a high drug loading capacity in this system may be attributed to the high surface area of the atomic-thin layers of $\mathrm{MoS}_{2} /$ GO nanocomposites. Third, the hydroxy and carboxyl groups on GO nanosheets can also form a strong hydrogen-bonding interaction with hydroxy and amino groups on DOX.28,32,61 Owing to these interactions, DOX can be nicely loaded onto $\mathrm{MoS}_{2} / \mathrm{GO}$ nanocomposites.

Thereafter, the materials loaded with DOX were assessed for the tumor-killing efficacy in vitro and in vivo. Since $\mathrm{MoS}_{2} / \mathrm{GO}$ composites displayed preferential localization into the lung, we deliberately selected lung tumor cells and other tumor cells that have the propensity to metastasize to the lung in this assessment. Owing to differential sensitivity for each cell type to DOX, different cell types were treated with DOX-loaded materials at customized concentrations. Lewis lung carcinoma cells were first subjected to various DOXloaded materials at the same mass concentration, $2 \mu \mathrm{g} \mathrm{ml}^{-1}$. As shown in Figure 4b, $\mathrm{MoS}_{2} / \mathrm{GO} @ \mathrm{DOX}$ manifested the greatest inhibition on cell growth (by $>71 \%, P<0.001$ ), followed by GO@DOX (by approximately 58\%, $P<0.001$ ), FA- $\mathrm{MoS}_{2} @ D O X$ (by about 35\%, $P<0.001$ ) and Lys-MoS $2 @ D O X$ (by $\sim 22 \%, P<0.001$ ), in line with the DOX loading results (Figure 4a). Furthermore, we determined the tumor-killing efficacy in non-lung tumor cells that possessed the propensity to metastasize to the lung. Consistent with the observations in Lewis lung carcinoma cells, the greatest suppression was found for $\mathrm{MoS}_{2} / \mathrm{GO} @ \mathrm{DOX}$ in B16 mouse melanoma cells, 4T1 breast cancer cells (here termed as the original 4T1 cells), ${ }^{38} 4 \mathrm{~T} 1$ cells with enhanced lung metastasis (termed as the lung-metastatic $4 \mathrm{~T} 1$ cells), ${ }^{38}$ and MDA- 
a

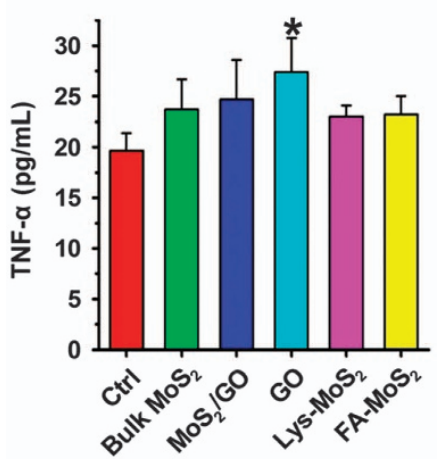

b

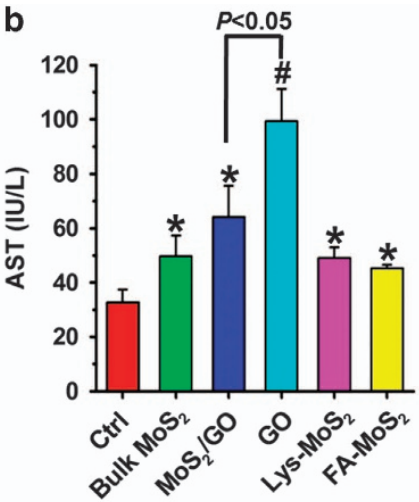

c

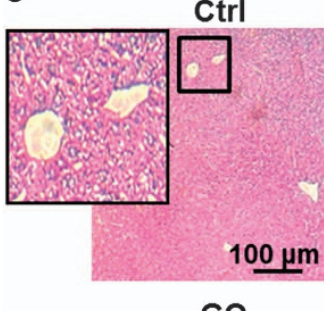

GO

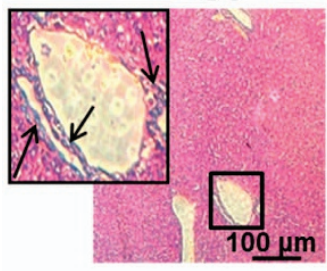

d

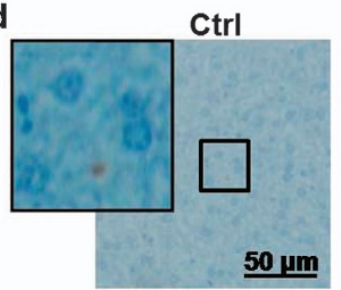

GO

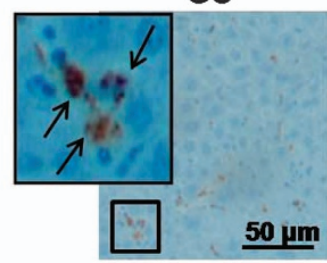

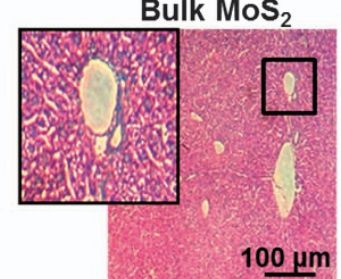

Lys-MoS

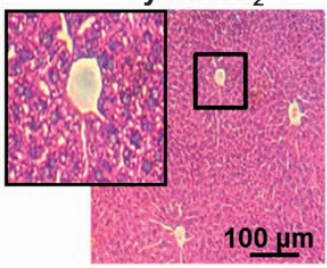

Bulk $\mathrm{MoS}_{2}$

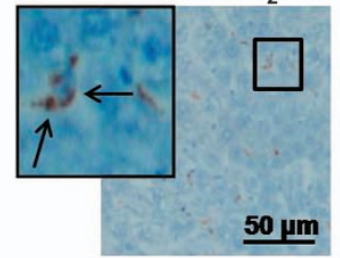

Lys-MoS

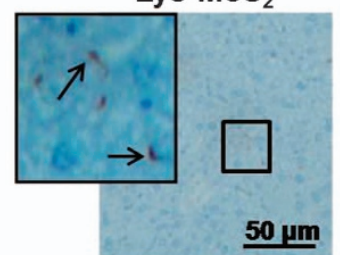

$\mathrm{MoS}_{2} / \mathrm{GO}$

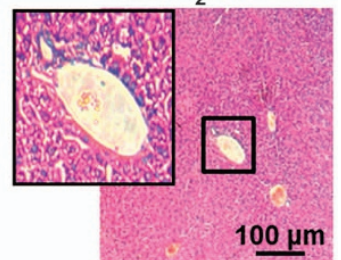

FA-MoS ${ }_{2}$

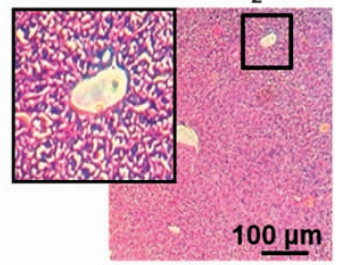

$\mathrm{MoS}_{2} / \mathrm{GO}$

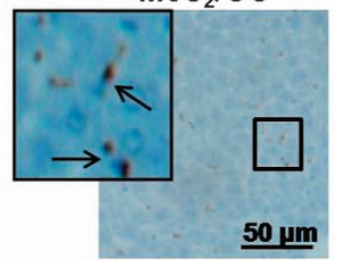

FA-MoS

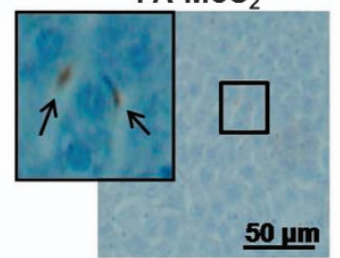

Figure 5 Blood biochemistry and histological examination in mice challenged by different materials. (a) Levels of pro-inflammatory cytokine TNF- $\alpha$ in sera from mice administrated with different nanomaterials for $24 \mathrm{~h}$. (b) AST levels in sera from mice treated with various nanomaterials for $24 \mathrm{~h}$. (c) H\&E staining of livers from the above treated mice. Original magnification, $\times 100$. Arrows indicate an enlarged central vein and infiltration of inflammatory cells around central veins in hepatic lobules. (d) Immunohistochemical staining of macrophages using an Ab against CD68 in liver sections from the above treated mice. Arrows denote CD68-positive macrophages. Original magnification, $\times 200$. There were six mice in each group $(n=6)$. Asterisk $\left(^{*}\right)$ : $P<0.05 ;$ pound sign (\#): $P<0.001$, compared to untreated control. TNF, tumor necrosis factor; AST, aspartate aminotransferase; H\&E, hematoxylin and eosin.

MB-231 human breast cancer cells (Figure 4b and Supplementary Figure $S 8, P<0.05)$. Together, these findings further corroborated the enhanced capacity of DOX loading and thus elevated tumor-killing efficacy for $\mathrm{MoS}_{2} / \mathrm{GO}$ nanocomposites relative to individual $\mathrm{MoS}_{2}$ and GO monomers.

Furthermore, the in vivo anti-tumor efficacy of $\mathrm{MoS}_{2} / \mathrm{GO}$ was evaluated in C57BL/6 mice using a lung metastasis model. Given that B16 murine melanoma cancer cells harbor favorable and selective propensity to metastasize to the lung, ${ }^{62,63}$ we used this model to determine the anti-tumor effect of $\mathrm{MoS}_{2} / \mathrm{GO}$ by making best use of its preferential lung targeting capability. As shown in Supplementary Figure S9A, there was no significant difference in body weight among all groups, and no abnormal activities (for example, diet and moving) were observed for all mice, ruling out the occurrence of gross toxicity to mice treated with these materials. Consistent with the in vitro data (Figure $4 \mathrm{~b}$ and Supplementary Figure S8), $\mathrm{MoS}_{2} / \mathrm{GO} @ D O X$ and 
a

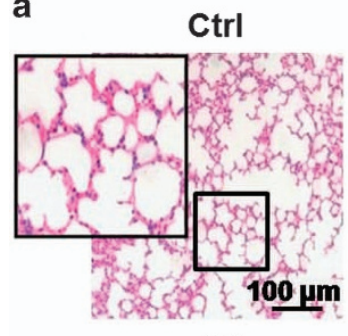

GO

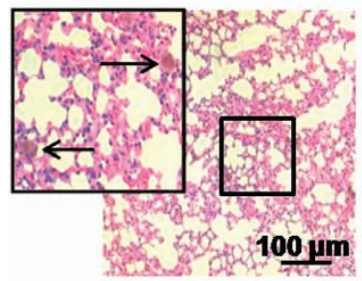

b

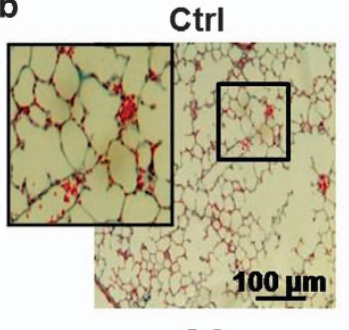

GO

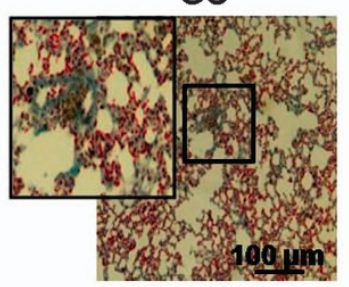

Bulk $\mathrm{MoS}_{2}$

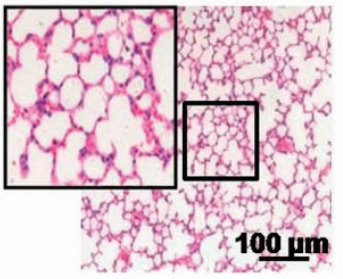

Lys-Mos

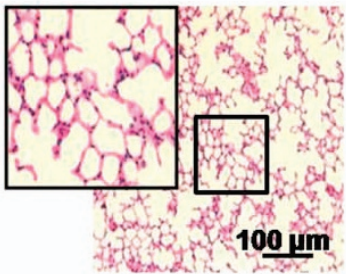

Bulk MoS

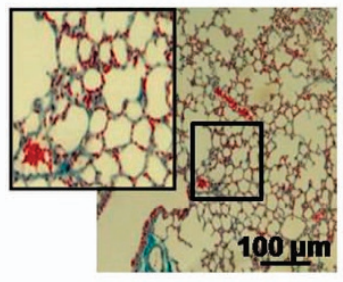

Lys-Mos 2

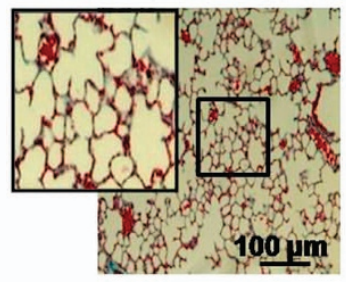

$\mathrm{MoS}_{2} / \mathrm{GO}$

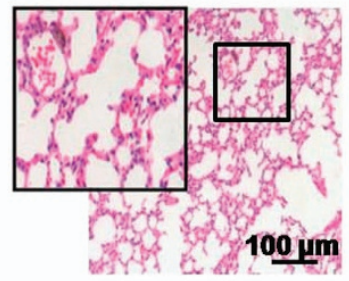

FA-MoS

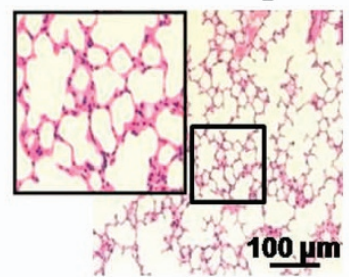

$\mathrm{MoS}_{2} / \mathrm{GO}$

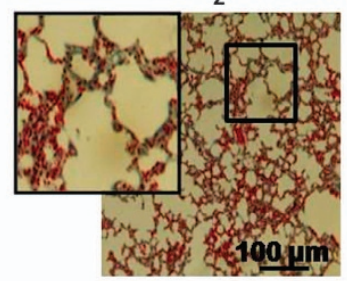

FA-MoS $_{2}$

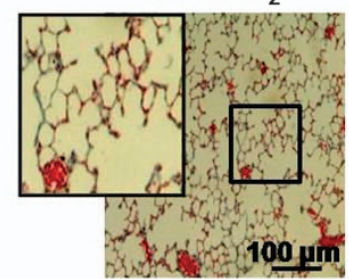

C

Ctrl
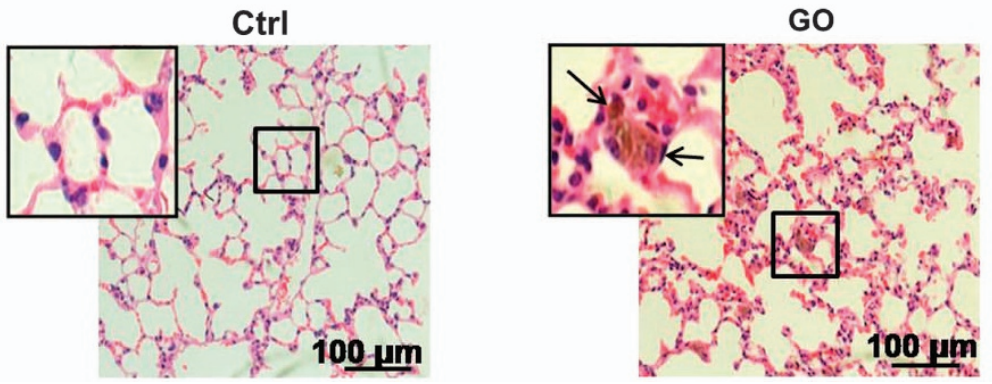

Figure 6 Histological analysis of lung injuries from mice treated with materials for $24 \mathrm{~h}$. Representative sections of lungs with (a) H\&E staining (original magnification, $\times 100$ ) and (b) Masson's trichrome staining (original magnification, $\times 100$ ). For H\&E staining in (a), the line squares stand for enlarged images of typical pulmonary alveoli. Arrows indicate the GO-cell complexes in lung tissues. For Masson's trichrome staining in (b), blue staining indicates collagen in lungs. (c) Representative enlarged images of lung sections with H\&E staining (original magnification, $\times 100$ ) from mice treated with PBS or GO. Black arrows denote the GO-cell complexes in lungs. H\&E, hematoxylin and eosin; GO, graphene oxide; PBS, phosphate-buffered saline.

GO@DOX remarkably inhibited the growth of metastatic tumors in the lung by $65-75 \%$, relative to untreated control (Figure $4 \mathrm{c}$ and Supplementary Figure S9B, $P<0.001$ ). By contrast, $\mathrm{MoS}_{2} / \mathrm{GO}, \mathrm{DOX}$ and Lys- $\mathrm{MoS}_{2} @ \mathrm{DOX}$ only slightly repressed the growth of metastatic tumors in the lung (Figure $4 \mathrm{c}$ and Supplementary Figure S9B). These data further supported the outstanding properties of $\mathrm{MoS}_{2} / \mathrm{GO}$ in lung targeting, drug loading and tumor-killing efficacy, and also recognized a promising application of $\mathrm{MoS}_{2} / \mathrm{GO}$ in treating cancers prone to the lung.
$\mathrm{MoS}_{2} / \mathrm{GO}$ composites provoked weaker inflammation and tissue injuries than monomers

Afterwards, the biosafety of $\mathrm{MoS}_{2} / \mathrm{GO}$ materials was thoroughly assessed. First, the general toxicity was determined in mice through i.v. administration of the materials for $24 \mathrm{~h}$. Consistent with the proinflammatory effects of GO materials, ${ }^{9,10}$ significant systemic inflammatory response was observed in GO-exposed mice, as evidenced by $40 \%$ increase of serum TNF- $\alpha$ concentration in GO-treated mice, compared to untreated mice (Figure $5 \mathrm{a}, \mathrm{P}<0.05$ ). By contrast, much 
milder increase of serum TNF- $\alpha$ was observed in mice treated with bulk $\mathrm{MoS}_{2}$, Lys-MoS 2 , FA-MoS 2 and $\mathrm{MoS}_{2} / \mathrm{GO}$, compared to GOtreated mice (Figure 5a), indicating compromised pro-inflammatory reactions due to the existence of $\mathrm{MoS}_{2}$ materials.

Further, tissue injuries were examined. Since liver is the prominent site for nanomaterial deposition, we first looked into liver injuries. As shown in Figure 5b, more than threefold increase of serum aspartate aminotransferase level was found in GO-treated mice relative to untreated mice $(P<0.001)$, revealing significant hepatoxicity induced by GO. By contrast, only a slight increase of aspartate aminotransferase level was recognized in mice challenged by bulk $\mathrm{MoS}_{2}$, Lys-MoS 2 , FA$\mathrm{MoS}_{2}$ and $\mathrm{MoS}_{2} / \mathrm{GO}$, compared to untreated mice (Figure 5b). Importantly, more than $35 \%$ reduction of aspartate aminotransferase level was observed in mice responding to $\mathrm{MoS}_{2} / \mathrm{GO}$, relative to GOtreated mice (Figure $5 \mathrm{~b}, \mathrm{P}<0.05$ ), confirming decreased hepatoxicity induced by $\mathrm{MoS}_{2} / \mathrm{GO}$ in comparison to GO. To validate these results, hematoxylin and eosin staining was performed in liver sections. In agreement with the above findings, GO-induced hepatoxicity was most severe, as reflected by enlarged central veins and infiltration of inflammatory leukocytes (denoted by arrows) (Figure 5c). To define the infiltration of macrophages in liver, immunohistochemical staining was carried out in liver sections using a CD68 Ab to recognize macrophages. ${ }^{64}$ As shown in Figure $5 \mathrm{~d}$, a number of macrophages were identified in liver sections from mice responding to GO, as
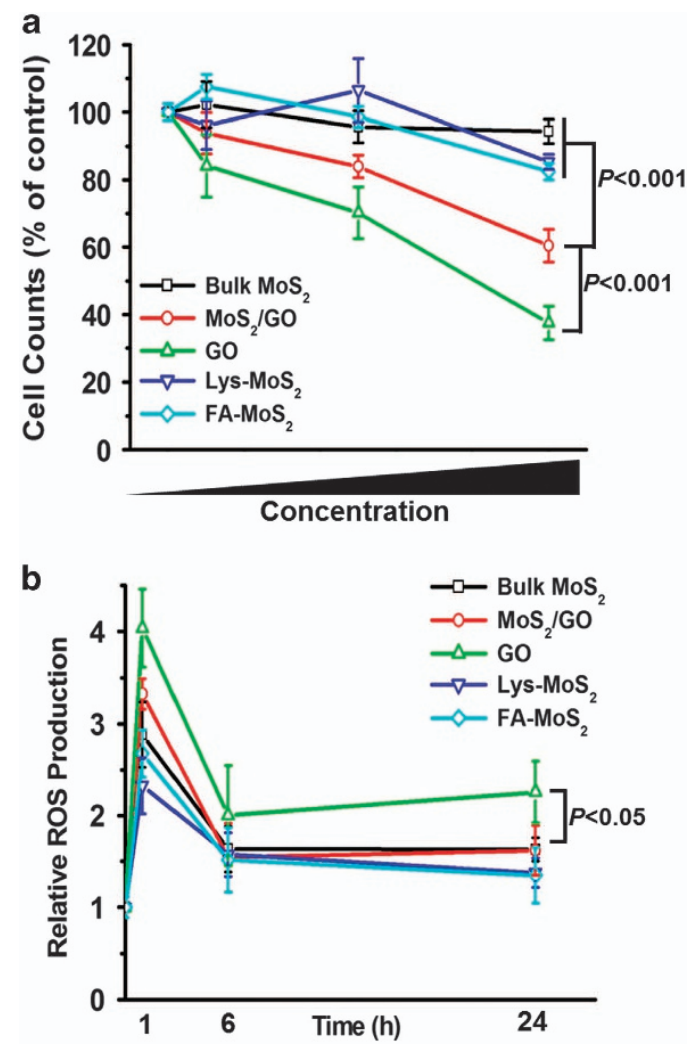

Figure 7 Cytotoxicity determination in J774A.1 cells responding to different materials. (a) Cell counting of J774A.1 cells exposed to materials for $24 \mathrm{~h}$ $(n=5)$. The concentrations of $\mathrm{MoS}_{2} / \mathrm{GO}$ were 10,50 and $100 \mu \mathrm{g} \mathrm{ml}-1$, whereas bulk $\mathrm{MoS}_{2}, \mathrm{GO}$ and $\mathrm{MoS}_{2}$ derivatives were at the same mass concentrations proportional to the component ratio within $\mathrm{MoS}_{2} / \mathrm{GO}$ composites. (b) Intracellular ROS production in J774A.1 cells in response to nanomaterials for 1,6 and $24 \mathrm{~h}(n=5)$. The concentrations were $5 \mu \mathrm{g} \mathrm{ml}^{-1}$ for $\mathrm{MoS}_{2} / \mathrm{GO}, 2.9 \mu \mathrm{g} \mathrm{ml}^{-1}$ for GO and $2.1 \mu \mathrm{g} \mathrm{ml}{ }^{-1}$ for bulk MoS 2 , Lys-MoS 2 and $\mathrm{FA}-\mathrm{MoS}_{2} . \mathrm{MoS}_{2}$, molybdenum disulfide; GO, graphene oxide. shown in brown color (indicted by arrows). In comparison, much milder macrophage infiltration was seen in mice challenged by bulk $\mathrm{MoS}_{2}$, Lys-MoS, FA-MoS 2 and $\mathrm{MoS}_{2} / \mathrm{GO}$.

Additionally, lung injuries were assessed through hematoxylin and eosin staining and Masson's trichrome staining. In analogy to our recent reports, ${ }^{9,10,46} \mathrm{GO}$ accumulation resulted in extensive lung injuries, as evidenced by extensive alveolar collapse, alveolar wall thickening and inflammatory cell infiltration, suggestive of increased collagen (Figure 6a). Inflammation and fibrosis are two interwined processes for the development of lung disorders, and inflammatory responses will contribute to progression of fibrosis through production of inflammatory cytokines that trigger the activation and maturation of fibroblasts into myofibroblasts. ${ }^{65,66}$ Masson's trichrome staining further verified the enhanced collagen secretion in alveoli and bronchioles (denoted by blue color within lung tissues), diagnostic of prospective lung fibrosis in mice responding to GO (Figure 6b). In parallel to these phenotypes, GO accumulation could be visualized in the lung, as characterized by dark spots representative of GO-cell complexes (indicated by arrows) (Figure 6a and c), analogous to previous studies. ${ }^{67}$ In stark contrast, no significant damages were observed in lung sections from mice administrated with bulk $\mathrm{MoS}_{2}$, Lys- $\mathrm{MoS}_{2}, \mathrm{FA}-\mathrm{MoS}_{2}$ and $\mathrm{MoS}_{2} / \mathrm{GO}$ (Figure 6a and b). Plus, no observable pathological alterations were recognized in hearts, spleens and kidneys in all treated mice by these materials (Supplementary Figures S10-S12).

\section{Decreased capability of $\mathrm{MoS}_{2} / \mathrm{GO}$ composites to associate with macrophages relative to $\mathrm{GO}$}

Given that $\mathrm{MoS}_{2} / \mathrm{GO}$ greatly ameliorated GO-induced pro-inflammatory effects, as demonstrated by the above findings, we therefore attempted to elucidate the underlying molecular mechanism. In response to the intrusion of nanoparticles in the body, macrophages are certainly the most important responsive cells to perform phagocytosis and secret pro-inflammatory cytokines, leading to leukocyte recruitment and other resultant processes, such as fibrosis. ${ }^{9,68}$ Since we observed significant inflammation and macrophage activation in mice challenged by GO and much less by $\mathrm{MoS}_{2} / \mathrm{GO}$ composite, we thus chose J774A.1 macrophages for the mechanistic investigation of nanomacrophage interaction. First, cytotoxicity was surveyed upon various materials through different approaches. As shown in Figure $7 \mathrm{a}$, in agreement with the above findings that GO was the most reactive material of those tested here, the cell number considerably dropped in a dose-dependent manner $(P<0.001)$, and a $15 \%$ decline of cell number was observed even at the lowest concentration of $10 \mu \mathrm{g} \mathrm{ml}^{-1}$. Nevertheless, $\mathrm{MoS}_{2} / \mathrm{GO}$ markedly reduced the cytotoxicity of GO by nearly $40 \%$ (Figure 7a, $\mathrm{P}<0.001$ ). Meanwhile, bulk $\mathrm{MoS}_{2}$, Lys- $\mathrm{MoS}_{2}$ and FA- $\mathrm{MoS}_{2}$ exhibited minimal toxicity to J774A.1 cells at various concentrations, implying desirable cytocompatibility of $\mathrm{MoS}_{2}$ materials. It is well established that macrophages upon exposure of nanomaterials would generate oxidative stress by provoking ROS production. ${ }^{9,10,22}$ Thus, intracellular ROS generation was determined. As shown in Figure $7 \mathrm{~b}$, the ROS burst was found in cells at $1 \mathrm{~h}$ after treatment with all materials, with a significant decline at 6 and $24 \mathrm{~h}$ $(P<0.05)$. Meanwhile, the greatest induction of ROS was found in cells treated with GO at all time points, compared to cells treated with other materials (Figure $7 \mathrm{~b}, \mathrm{P}<0.05$ ), in support of the cytotoxicity assay (Figure 7a). Of note, $\mathrm{MoS}_{2} / \mathrm{GO}$ stimulated much less ROS than GO $(P<0.05)$, comparable to bulk $\mathrm{MoS}_{2}$, Lys- $\mathrm{MoS}_{2}$ and FA-MoS (Figure $7 \mathrm{~b}$ ). Similar tendency was also observed for ROS production within $1 \mathrm{~h}$ at an interval of every $5 \mathrm{~min}$ (Supplementary Figure S13). 


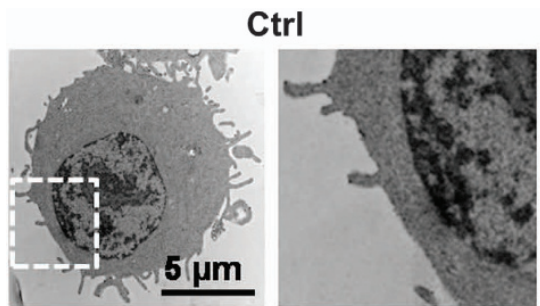

$\mathrm{MoS}_{2} / \mathrm{GO}$

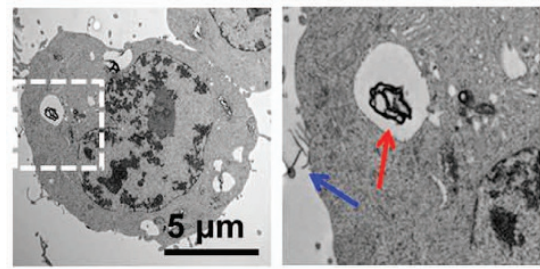

Lys-MoS
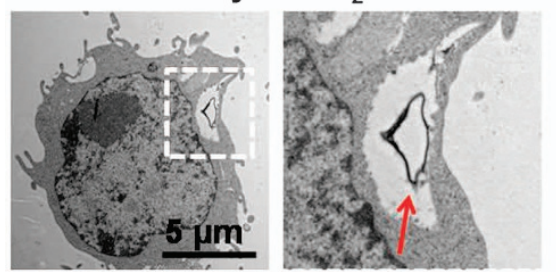

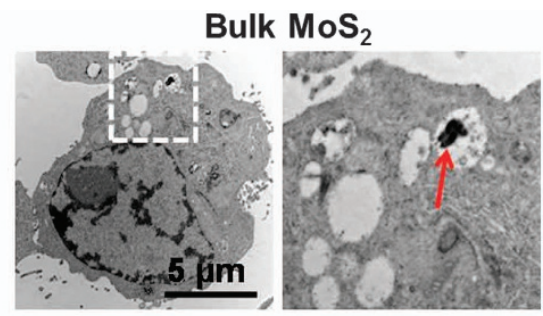

GO

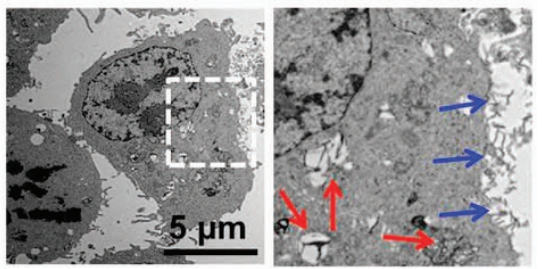

FA-MoS

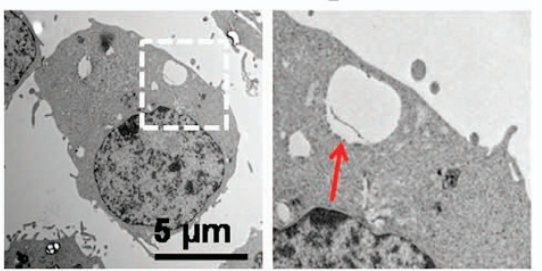

Figure 8 Cellular localization of materials in J774A.1 cells. High-resolution TEM images (original magnification, $\times 10000$ ) of treated cells at $5 \mu \mathrm{g} \mathrm{ml^{-1 }}$ for $\mathrm{MoS}_{2} / \mathrm{GO}, 2.9 \mu \mathrm{g} \mathrm{ml}^{-1}$ for GO and $2.1 \mu \mathrm{g} \mathrm{ml}-1$ for bulk $\mathrm{MoS}_{2}$, Lys-MoS 2 and FA-MoS 2 for $24 \mathrm{~h}$. Representative association of nanomaterials on plasma membrane (blue arrows) and inside phagosomes (red arrows) were indicated in the enlarged images (right) from the dash line squares. TEM, transmission electron microscopy; $\mathrm{MoS}_{2}$, molybdenum disulfide; GO, graphene oxide.

These results therefore revealed that GO-associated toxicity could be greatly ameliorated by the addition of $\mathrm{MoS}_{2}$.

Next, to closely interrogate the molecular mechanism responsible for compromised cytotoxicity for $\mathrm{MoS}_{2} / \mathrm{GO}$, we shed light on the nano-bio interface. To avoid extensive cell death that will interfere with mechanistic investigation, a sublethal concentration at $5 \mu \mathrm{g} \mathrm{ml} l^{-1}$ was deliberately chosen in the following experiments. As shown in Figure 8, TEM analysis displayed significant cellular uptake for all materials by macrophages, especially for GO-treated cells, as evidenced by phagocytosed nanoparticles in membrane-bound structures inside phagosomes within the cytosol (Figure 8, denoted by red arrows). Meanwhile, similar to our recent data, ${ }^{9}$ there was an active association between GO sheets with plasma membrane, as characterized by the massive adsorption of GO sheets on plasma membrane in parallel, without showing the sign of phagocytosis (Figure 8 , indicted by blue arrows). To a much less extent, only a few sheets could be visualized on plasma membrane in $\mathrm{MoS}_{2} / \mathrm{GO}$-treated cells (denoted by a blue arrow), whereas no sheet could be found on plasma membrane in cells treated with bulk $\mathrm{MoS}_{2}$, Lys- $\mathrm{MoS}_{2}$ and FA-MoS (Figure 8).

We recently demonstrated that GO with larger lateral size could readily adhere to plasma membrane and thus be internalized by macrophages, leading to macrophagic activation. ${ }^{9}$ Analogously, previous studies also demonstrated that GO actively interacts with cell plasma through the abundant oxygen-containing functional groups on its surface. ${ }^{69,70}$ As a result, the association of the flat side with plasma membrane would trigger macrophage activation into the M1 subtype with pro-inflammatory effects. ${ }^{9,71,72}$ Different from GO, $\mathrm{MoS}_{2}$ materials harbored much weaker interaction with plasma membrane, possibly due to the absence of active oxygen-containing functional groups on their surface. ${ }^{69,73}$ By contrast, $\mathrm{MoS}_{2} / \mathrm{GO}$ displayed a reduced capability to interact with plasma membrane, presumably being ascribed to the existence of $\mathrm{MoS}_{2}$. Moreover, macrophages are a vital type of immune cells in recognizing and interacting with nanomaterials, which may further lead to phagocytosis and clearance of extraneous nanomaterials. ${ }^{74,75}$ As shown in the TEM images (Figure 8), $\mathrm{MoS}_{2} / \mathrm{GO}$ manifested reduced capability to adsorb onto plasma membrane, associated with compromised phagocytosis, compared with GO. This finding thus implied less loss of drug delivered by $\mathrm{MoS}_{2} / \mathrm{GO}$ due to the clearance of macrophages, giving rise to enhanced capacity of $\mathrm{MoS}_{2} / \mathrm{GO} @ \mathrm{DOX}$ nanocomposites to kill tumor cells through this mechanism.

\section{Mitigated ability of $\mathrm{MoS}_{2} / \mathrm{GO}$ composites to activate macrophages} relative to $\mathrm{GO}$

Downstream of macrophagic activation, pro-inflammatory cytokines (for example, interleukin-6 and TNF- $\alpha$ ) will be induced to enhance inflammatory reactions. ${ }^{76,77}$ In agreement with the in vivo results (Figure 5a), exaggerated elevation of secreted TNF- $\alpha$ was observed in GO-treated cells, relative to untreated cells (Figure 9a, P<0.001), and this elevation was diminished by $27 \%$ in cells treated with $\mathrm{MoS}_{2} / \mathrm{GO}$, compared to GO-treated cells (Figure $9 \mathrm{a}, \mathrm{P}<0.001$ ). In support of this finding, similar results were found for interleukin-6 production (Figure 9b). Importantly, these data pointed out that $\mathrm{MoS}_{2} / \mathrm{GO}$ consistently instigated less production of TNF- $\alpha$ and interleukin-6 proteins than GO (Figure 9a and $b$ ).

In addition to pro-inflammatory cytokines, activated macrophages also secrete other chemokines that are necessary for cascade immune responses. ${ }^{78,79}$ As shown in Figure 9c, MCP-1 (also referred to CCL2) was elevated approximately by twofold in cells upon GO $(P<0.001)$, and this induction was diminished by $>25 \%$ in cells upon $\mathrm{MoS}_{2} / \mathrm{GO}$ 
a

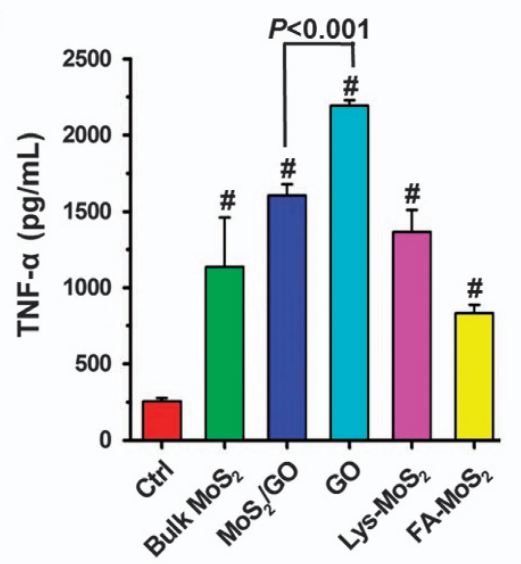

C

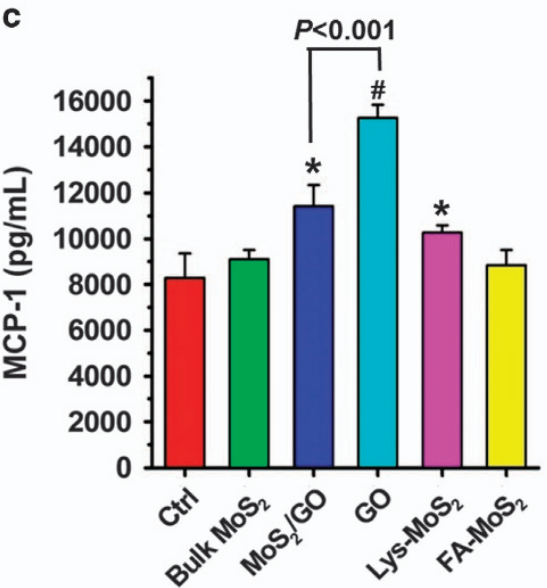

e

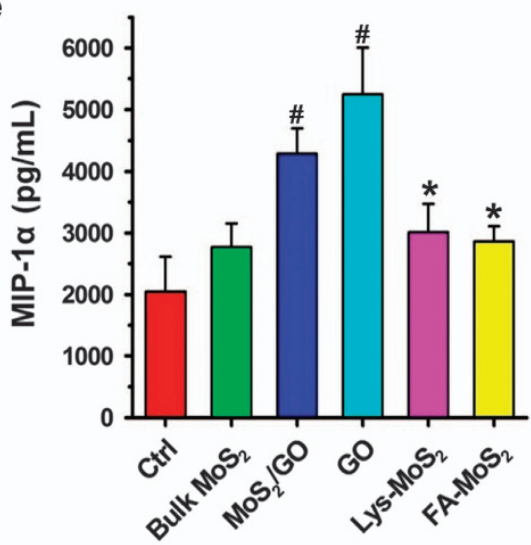

b

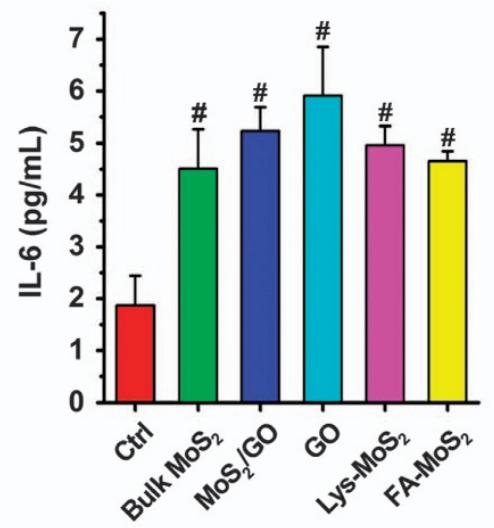

d

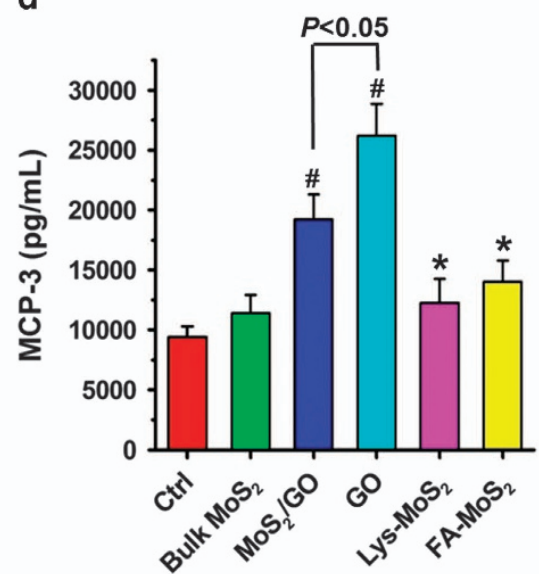

Figure 9 Pro-inflammatory responses elicited by diverse materials in J774A.1 cells. Concentrations of secreted pro-inflammatory cytokines for (a) TNF- $\alpha$ and (b) IL-6, and chemokines for (c) MCP-1, (d) MCP-3 and (e) MIP- $1 \alpha$ in cell culture media after cells were treated with nanomaterials for $24 \mathrm{~h}(n=5)$. The exposure doses were $20 \mu \mathrm{g} \mathrm{ml}^{-1}$ for $\mathrm{MoS}_{2} / \mathrm{GO}, 11.6 \mu \mathrm{g} \mathrm{ml}-1$ for GO and $8.4 \mu \mathrm{g} \mathrm{ml} \mathrm{l}^{-1}$ for bulk $\mathrm{MoS}_{2}$, Lys-MoS 2 and FA-MoS 2 . Asterisk $(*)$ indicates $P<0.05$ and pound sign (\#) denotes $P<0.001$, compared to untreated control. TNF, tumor necrosis factor; IL-6, interleukin-6; MoS 2 , molybdenum disulfide; GO, graphene oxide; MCP, monocyte chemotactic protein; MIP, macrophage inflammatory protein.

$(P<0.001)$. Likewise, similar findings were demonstrated for the induction of MCP-3 (namely CCL7) and macrophage inflammatory protein-1 $\alpha$ (that is, CCL3) (Figures $9 \mathrm{~d}$ and e, $\mathrm{P}<0.05$ ). These changes were also verified at the mRNA levels for MCP-1, MCP-3 and macrophage inflammatory protein- $1 \alpha$ (Supplementary Figure S14). Since these chemokines function to recruit differential leukocytes to inflammation sites, ${ }^{79}$ our results suggested differential proinflammatory effects by these materials with compromised capability for $\mathrm{MoS}_{2} / \mathrm{GO}$ in comparison to GO. These results further stressed the important discovery of diminished bioreactivity of $\mathrm{MoS}_{2} / \mathrm{GO}$ towards macrophages relative to GO, which was accounted for the addition of $\mathrm{MoS}_{2}$. For $\mathrm{MoS}_{2}$, it is relatively more biocompatible than GO when comparing their in vitro and in vivo toxicity, because $\mathrm{MoS}_{2}$ is rather inactive to biomolecules. ${ }^{80,81}$ Considered together, these findings signified the improved biocompatibility of $\mathrm{MoS}_{2} / \mathrm{GO}$ nanocomposites for potential biomedical applications. 


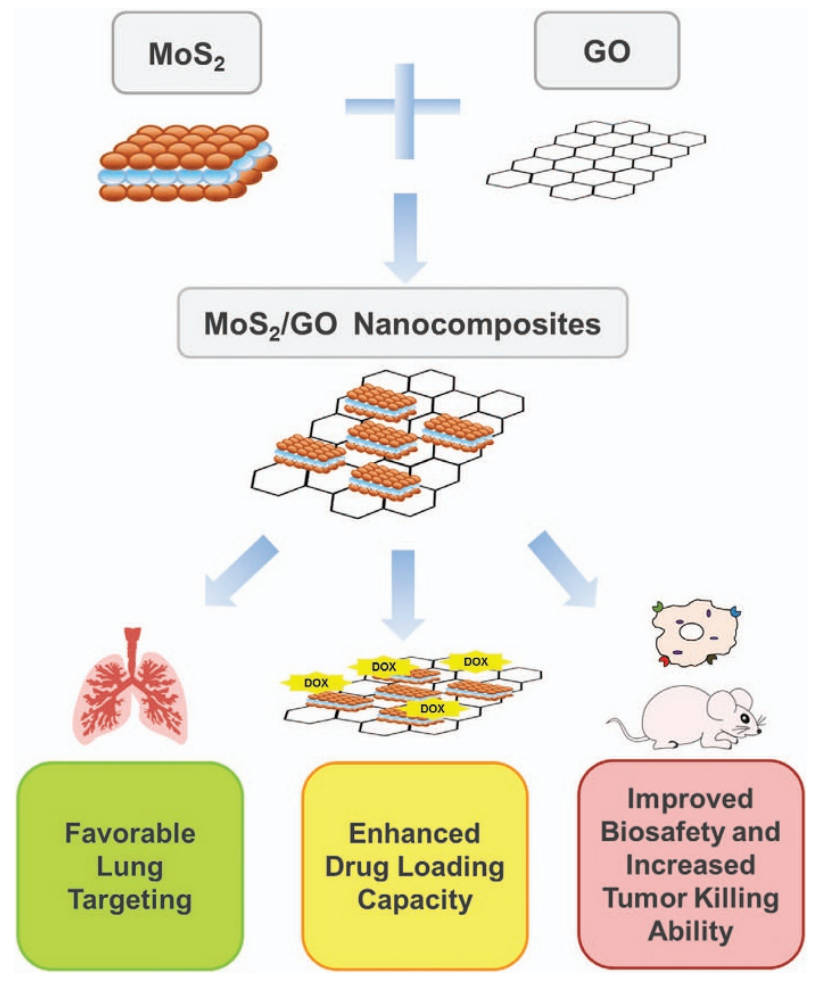

Figure 10 The overall schematic diagram depicting the functionality and biocompatibility enhancement through synthesizing the $\mathrm{MoS}_{2} / \mathrm{GO}$ nanocomposites.

\section{CONCLUSIONS}

In the current study, through rational design we synthesized $\mathrm{MoS}_{2} / \mathrm{GO}$ nanocomposites and conducted extensive characterizations to determine their physicochemical properties, functionalities for cancer nanotheranostics, biosafety profile and nano-bio interactions, as delineated in Figure 10. In short, $\mathrm{MoS}_{2} / \mathrm{GO}$ nanocomposites possessed favorable properties from both $\mathrm{MoS}_{2}$ and GO. First of all, $\mathrm{MoS}_{2} / \mathrm{GO}$ composites harbored desirable dispersity in aqueous solutions due to the contribution of GO. Second, $\mathrm{MoS}_{2} / \mathrm{GO}$ revealed much better biocompatibility both in vitro and in vivo compared to GO itself, with reduced pro-inflammatory effects, ameliorated lung fibrosis and compromised macrophagic activation, due to the reduced reactivity of $\mathrm{MoS}_{2}$ in the composites. Most importantly, $\mathrm{MoS}_{2} / \mathrm{GO}$ manifested a novel property, that is, the composites selectively gathered in the lung, revealing a pronounced tendency of lung localization comparable to GO itself. This property would endow the material with a 'guided missile' effect to target the lung. Moreover, $\mathrm{MoS}_{2} / \mathrm{GO}$ composites displayed greater drug loading capacity than GO and $\mathrm{MoS}_{2}$ alone. Owing to these preferential properties, $\mathrm{MoS}_{2} / \mathrm{GO}$ composites revealed enhanced tumor-killing efficacy against lung cancer cells and various cancer cells that have the propensity to metastasize to the lung, and $\mathrm{MoS}_{2} / \mathrm{GO}$ substantially leashed metastatic tumor growth of B16 murine melanoma cancer cells in lungs of mice. With regard to the nano-bio interactions, we uncovered the molecular mechanisms that dictated the association and subsequent uptake of nanosheets by macrophages. Namely, GO was more prone to interact with macrophages, resulting in phagocytosis and macrophagic activation through membrane association, whereas $\mathrm{MoS}_{2} / \mathrm{GO}$ was relatively reluctant to react towards macrophages due to the lack of active oxygen-containing functional group on its surface. Thus, our combined data unearthed remarkable physicochemical and functional properties of $\mathrm{MoS}_{2} / \mathrm{GO}$ nanocomposites with improved cyto-/biocompatibility (Figure 10), holding a great translational significance for potential applications in biomedicine, such as cancer nanotheranostics.

\section{CONFLICT OF INTEREST}

The authors declare no conflict of interest.

\section{ACKNOWLEDGEMENTS}

This work was supported by a grant under the national '973' program (grant number: 2014CB932000), the Strategic Priority Research Program of the Chinese Academy of Sciences (Grant No. XDB14000000) and grants from the National Natural Science Foundation of China (grant numbers: 21607157, 21425731 and 21637004). We thank the laboratory members for reagents and assistance with experiments.

\section{PUBLISHER'S NOTE}

Springer Nature remains neutral with regard to jurisdictional claims in published maps and institutional affiliations.

1 Siegel, R. L., Miller, K. D. \& Jemal, A. Cancer statistics, 2016. CA-Cancer J. Clin. 66 7-30 (2016).

2 Torre, L. A., Siegel, R. L. \& Jemal, A. Lung cancer statistics. Adv. Exp. Med. Biol. 893, 1-19 (2016).

3 Massague, J. \& Obenauf, A. C. Metastatic colonization by circulating tumour cells. Nature 529, 298-306 (2016).

4 Lambert, A. W., Pattabiraman, D. R. \& Weinberg, R. A. Emerging biological principles of metastasis. Cell 168, 670-691 (2017).

5 Chen, Y., Wu, Y., Sun, B., Liu, S. \& Liu, H. Two-dimensional nanomaterials for cancer nanotheranostics. Small 13, 1603446 (2017).

6 Jang, C., Lee, J. H., Sahu, A. \& Tae, G. The synergistic effect of folate and RGD dual ligand of nanographene oxide on tumor targeting and photothermal therapy in vivo. Nanoscale 7, 18584-18594 (2015).

7 Corchero, J. L. \& Villaverde, A. Biomedical applications of distally controlled magnetic nanoparticles. Trends Biotechnol. 27, 468-476 (2009).

8 Wang, Z. L., Qiao, R. R., Tang, N., Lu, Z. W., Wang, H., Zhang, Z. X., Xue, X. D., Huang, Z. Y., Zhang, S. R., Zhang, G. X. \& Li, Y. P. Active targeting theranostic iron oxide nanoparticles for MRI and magnetic resonance-guided focused ultrasound ablation of lung cancer. Biomaterials 127, 25-35 (2017).

9 Ma, J., Liu, R., Wang, X., Liu, Q., Chen, Y. N., Valle, R. P., Zuo, Y. Y., Xia, T. \& Liu, S. J. Crucial role of lateral size for graphene oxide in activating macrophages and stimulating pro-inflammatory responses in cells and animals. ACS Nano 9, 10498-10515 (2015).

10 Xu, M., Zhu, J. Q., Wang, F. F., Xiong, Y. J., Wu, Y. K., Wang, Q. Q., Weng, J., Zhang, Z. H., Chen, W. \& Liu, S. J. Improved in vitro and in vivo biocompatibility of graphene oxide through surface modification: poly(acrylic acid)-functionalization is superior to PEGylation. ACS Nano 10, 3267-3281 (2016).

11 Chen, S. M., Xiong, C. Q., Liu, H. H., Wan, Q. Q., Hou, J., He, Q., Badu-Tawiah, A. \& $\mathrm{Nie}, \mathrm{Z}$. X. Mass spectrometry imaging reveals the sub-organ distribution of carbon nanomaterials. Nat. Nanotechnol. 10, 176-182 (2015).

12 Nurunnabi, M., Khatum, Z., Huh, K. M., Park, S. Y., Lee, D. Y., Cho, K. J. \& Lee, Y. K. In vivo biodistribution and toxicology of carboxylated graphene quantum dots. ACS Nano 7, 6858-6867 (2013).

13 Liu, J. H., Yang, S. T., Wang, H. F., Chang, Y. L., Cao, A. N. \& Liu, Y. F. Effect of size and dose on the biodistribution of graphene oxide in mice. Nanomedicine 7 1801-1812 (2012).

14 Zhang, X. Y., Yin, J. L., Peng, C., Hu, W. Q., Zhu, Z. Y., Li, W. X., Fan, C. H. \& Huang, $Q$. Distribution and biocompatibility studies of graphene oxide in mice after intravenous administration. Carbon 49, 986-995 (2011).

15 Wen, K. P., Chen, Y., C., Chuang, C. H., Chang, H. Y., Lee, C. Y. \& Tai, N. H Accumulation and toxicity of intravenously-injected functionalized graphene oxide in mice. J.Appl. Toxicol. 35, 1211-1218 (2015).

16 Gao, J., Sanchez-Purra, M., Huang, H., Wang, S. H., Chen, Y. N., Yu, X. F., Luo, Q. Hamad-Schifferli, K. \& Liu, S. J. Synthesis of different-sized gold nanostars for Raman bioimaging and photothermal therapy in cancer nanotheranostics. Sci. China Chem. 60, 1219-1229 (2017).

17 Gustafson, H. H., Holt-Casper, D., Grainger, D. W. \& Ghandehari, H. Nanoparticle uptake: the phagocyte problem. Nano Today 10, 487-510 (2015).

18 Chen, Y., Xu, M., Zhang, J., Ma, J., Gao, M., Zhang, Z. H., Xu, Y. \& Liu, S. J. Genomewide DNA methylation variations upon exposure to engineered nanomaterials and their implications in nanosafety assessment. Adv. Mater. 29 (2017).

19 Yang, K., Li, Y.J., Tan, X. F., Peng, R. \& Liu, Z. Behavior and toxicity of graphene and its functionalized derivatives in biological systems. Small 9, 1492-1503 (2013).

20 Ou, L. L., Song, B., Liang, H. M., Liu, J., Feng, X. L., Deng, B., Sun, T. \& Shao, L. Q. Toxicity of graphene-family nanoparticles: a general review of the origins and mechanisms. Part. Fibre Toxicol. 13, 57 (2016). 
21 Yang, K., Feng, L. Y., Shi, X. Z. \& Liu, Z. Nano-graphene in biomedicine: theranostic applications. Chem. Soc. Rev. 42, 530-547 (2013).

22 Qu, G. B., Liu, S. J., Zhang, S. P., Wang, L., Wang, X. Y., Sun, B. B., Yin, N. Y., Gao, X., Xia, T., Chen, J. J. \& Jiang, G. B. Graphene oxide induces toll-like receptor 4 (TLR4)dependent necrosis in macrophages. ACS Nano 7, 5732-5745 (2013).

23 Wang, Q. H., Kalantar-Zadeh, K., Kis, A., Coleman, J. N. \& Strano, M.S. Electronics and optoelectronics of two-dimensional transition metal dichalcogenides. Nat. Nanotechnol. 7, 699-712 (2012)

24 Hersam, M. C. The reemergence of chemistry for post-graphene two-dimensional nanomaterials. ACS Nano 9, 4661-4663 (2015).

25 Service, R. F. Beyond garphene. Science 348, 490-492 (2015).

26 Li, X., Shan,, J. Y., Zhang, W. Z., Su, S., Yuwen, L. H. \& Wang, L. H. Recent advances in synthesis and biomedical applications of two-dimensional transition metal dichalcogenide nanosheets. Small 13 (2017)

27 Chen, Y., Tan, C. L., Zhang, H. \& Wang, L. Z. Two-dimensional graphene analogues for biomedical applications. Chem. Soc. Rev. 44, 2681-2701 (2015).

28 Liu, T., Wang, C., Gu, X., Gong, H., Cheng, L., Shi, X. Z., Feng, L. Z., Sun, B. Q. \& Liu, Z. Drug delivery with PEGylated $\mathrm{MoS}_{2}$ nano-sheets for combined photothermal and chemotherapy of cancer. Adv. Mater. 26, 3433-3440 (2014).

29 Liu, T., Shi, S. X., Liang, C., Shen, S. D., Cheng, L., Wang, C., Song, X. J., Goei, S., Barnhart, T. E., Cai, W. B. \& Liu, Z. Iron oxide decorated $\mathrm{MoS}_{2}$ nanosheets with double PEGylation for chelator-free radiolabeling and multimodal imaging guided photothermal therapy. ACS Nano 9, 950-960 (2015).

30 Santos-Silva, T., Ferroni, F., Thapper, A., Marangon, J., Gonzalez, P. J., Rizzi, A. C. Moura, I., Moura, J. J. G. \& Romao, M. J. Kinetic, structural, and EPR studies reveal that aldehyde oxidoreductase from Desulfovibrio gigas does not need a sulfido ligand for catalysis and give evidence for a direct Mo-C interaction in a biological system. J. Am. Chem. Soc. 131, 7990-7998 (2009).

31 Hossain, M.K., Haukka, M., Sillanpaa, R., Hrovat, D. A., Richmond, M. G., Nordlander, E. \& Lehtonen, A. Syntheses and catalytic oxotransfer activities of oxo molybdenum(vi) complexes of a new aminoalcohol phenolate ligand. Dal. Ton. T. 46, 7051-7060 (2017).

32 Yin, W.Y., Yan, L., Yu, J., Tian, G., Zhou, L. J., Zheng, X. P., Zhang, X., Yong, Y., Li, J., Gu, Z. J. \& Zhao, Y. L. High-throughput synthesis of single-layer $\mathrm{MoS}_{2}$ nanosheets as a near-infrared photothermal-triggered drug delivery for effective cancer therapy. ACS Nano 8, 6922-6933 (2014)

33 Kim, T.I., Kwon, B., Yoon, J., Park, I. J., Bang, G. S., Park, Y., Seo, Y. S. \& Choi, S. Y. Antibacterial activities of graphene oxide-molybdenum disulfide nanocomposite films. ACS Appl. Mater. Interfaces 9, 7908-7917 (2017).

34 Peng, J. \& Weng, J. Enhanced peroxidase-like activity of $\mathrm{MoS}_{2}$ /graphene oxide hybrid with light irradiation for glucose detection. Biosens. Bioelectron. 89, 652-658 (2017).

35 Yoon, J., Lee, T., Bapurao, G. B., Jo, J., Oh, B. K. \& Choi, J. W. Electrochemical $\mathrm{H}_{2} \mathrm{O}_{2}$ biosensor composed of myoglobin on $\mathrm{MoS}_{2}$ nanoparticle-graphene oxide hybrid structure. Biosens. Bioelectron. 93, 14-20 (2017).

36 Jia, J., Sun, L. P., Hu, N., Huang, G. M. \& Weng, J. Graphene enhances the specificity of the polymerase chain reaction. Small 8, 2011-2015 (2012).

37 Sun, L.P., Hu, N., Peng, J., Chen, L. Y. \& Weng, J. Ultrasensitive detection of mitochondrial DNA mutation by graphene oxide/DNA hydrogel electrode. Adv. Funct. Mater. 24, 6905-6913 (2014)

38 Guo, W. L., Zhang, S. P. \& Liu, S. J. Establishment of a novel orthotopic model of breast cancer metastasis to the lung. Oncol. Rep. 33, 2992-2998 (2015).

39 Dong, L., Liu, Y., Lu, Y., Zhang, L., Man, N., Cao, L., Ma, K., An, D., Lin, J., Xu, Y. J. Xu, W. P., Wu, W. B., Yu, S. H. \& Wen, L. P. Tuning magnetic property and autophagic response for self-assembled Ni-Co alloy nanocrystals. Adv. Funct. Mater. 23, 5930-5940 (2013).

40 Liu, Q.M., Song, L. W., Chen, S. A., Gao, J. Y., Zhao, P. Y. \& Du, J. Z. A superparamagnetic polymersome with extremely high T-2 relaxivity for MRI and cancer-targeted drug delivery. Biomaterials 114, 23-33 (2017).

41 Bhatia, D., Arumugam, S., Nasilowski, M., Joshi, H., Wunder, C., Chambon, V., Prakash, V., Grazon, C., Nadal, B., Maiti, P. K., Johannes, L., Dubertret, B. \& Krishnan, Y. Quantum dot-loaded monofunctionalized DNA icosahedra for single-particle tracking of endocytic pathways. Nat. Nanotechnol. 11, 1112-1119 (2016).

42 Wang, X., Mansukhani, N. D., Guiney, L. M., Ji, Z. X., Chang, C. H., Wang, M. Y., Liao, Y. P., Song, T. B., Sun, B. B., Li, R. B., Xia, T., Hersam, M. C. \& Nel, A. E. Differences in the toxicological potential of $2 \mathrm{D}$ versus aggregated molybdenum disulfide in the lung. Small 11, 5079-5087 (2015)

43 Becerril, H. A., Mao, J., Liu, Z., Stoltenberg, R. M., Bao, Z. \& Chen, Y. Evaluation of solution-processed reduced graphene oxide films as transparent conductors. ACS Nano 2, 463-470 (2008)

44 Eda, G., Yamaguchi, H., Voiry, D., Fujita, T., Chen, M. W. \& Chhowalla, M. Photoluminescence from chemically exfoliated $\mathrm{MoS}_{2}$. Nano Lett. 11, 5111-5116 (2011).

45 Tongay, S., Sahin, H., Ko, C., Luce, A., Fan, W., Liu, K., Zhou, J., Huang, Y. S., Ho, C. H., Yan, J. Y., Ogletree, D. F., Aloni, S., Ji, J., Li, S. S., Li, J. B., Peeters, F. M. \& Wu, J. Q. Monolayer behaviour in bulk ReS2 due to electronic and vibrational decoupling. Nat. Commun. 5, 3252 (2014)

46 Zhu, J. Q., Xu, M., Gao, M., Zhang, Z. H., Xu, Y., Xia, T. \& Liu, S. J. Graphene oxide induced perturbation to plasma membrane and cytoskeletal meshwork sensitize cancer cells to chemotherapeutic agents. ACS Nano 11, 2637-2651 (2017).

47 Anselmo, A. C. \& Mitragotri, S. Impact of particle elasticity on particle-based drug delivery systems. Adv. Drug. Deliv. Rev. 108, 51-67 (2017).

48 Shim, G., Kim, M. G., Park, J. Y. \& Oh, Y. K. Graphene-based nanosheets for delivery of chemotherapeutics and biological drugs. Adv. Drug. Deliv. Rev. 105, 205-227 (2016).
49 Sarkar, S., Osama, K., Jamal, Q. M. S., Kamal, M. A., Sayeed, U., Khan, M. K. A., Siddiqui, M.H. \& Akhtar, S. Advances and implications in nanotechnology for lung cancer management. Curr. Drug Metab. 18, 30-38 (2017).

50 Li, S. X., Wang, K. K., Shi, Y. J., Cui, Y. N., Chen, B. L., He, B., Dai, W. B., Zhang, H., Wang, X. Q., Zhong, C. L., Wu, H. N., Yang, Q. Y. \& Zhang, Q. Novel biological functions of ZIF-NP as a delivery vehicle: high pulmonary accumulation, favorable biocompatibility, and improved therapeutic outcome. Adv. Funct. Mater. 26, 2715-2727 (2016).

51 Barua, S. \& Mitragotri, S. Challenges associated with penetration of nanoparticles across cell and tissue barriers: a review of current status and future prospects. Nano Today 9, 223-243 (2014)

52 Li, N., Li, T. T., Hu, C., Lei, X. M., Zuo, Y. P. \& Han, H. Y. Targeted near-infrared fluorescent turn-on nanoprobe for activatable imaging and effective phototherapy of cancer cells. ACS Appl. Mater. Interfaces 8, 15013-15023 (2016).

53 Chen, J. Q., Liu, C. B., Zeng, G., You, Y. J., Wang, H. N., Gong, X. J., Zheng, R. Q., Kim, J., Kim, C. \& Song, L. Indocyanine green loaded reduced graphene oxide for in vivo photoacoustic/fluorescence dual-modality tumor imaging. Nanoscale Res. Lett. 11, 85 (2016).

54 Aggarwal, P., Hall, J. B., McLeland, C. B., Dobrovolskaia, M. A. \& McNeil, S. E. Nanoparticle interaction with plasma proteins as it relates to particle biodistribution, biocompatibility and therapeutic efficacy. Adv. Drug. Deliv. Rev. 61, 428-437 (2009).

55 Chrastina, A., Valadon, P., Massey, K. A. \& Schnitzer, J. E. Lung vascular targeting using antibody to aminopeptidase P: CT-SPECT imaging, biodistribution and pharmacokinetic analysis. J. Vasc. Res. 47, 531-543 (2010).

56 Massey, K. A. \& Schnitzer, J. E. Targeting and imaging signature caveolar molecules in lungs. Proc. Am. Thorac. Soc. 6, 419-430 (2009).

57 Sun, X. M., Liu, Z., Welsher, K., Robinson, J. T., Goodwin, A., Zaric, S. \& Dai, H. J. Nano-graphene oxide for cellular imaging and drug delivery. Nano Res. 1, 203-212 (2008)

58 Golshan, M., Salami-Kalajahi, M., Mirshekarpour, M., Roghani-Mamaqani, H. \& Mohammadi, M. Synthesis and characterization of poly(propylene imine)-dendrimergrafted gold nanoparticles as nanocarriers of doxorubicin. Colloid. Surface. B 155, 257-265 (2017).

59 Cheng, W., Nie, J. P., Xu, L., Liang, C. Y., Peng, Y., Liu, G., Wang, T., Mei, L., Huang, L. Q. \& Zeng, X. W. pH-sensitive delivery vehicle based on folic acid-conjugated polydopamine-modified mesoporous silica nanoparticles for targeted cancer therapy. ACS Appl. Mater. Interfaces 9, 18462-18473 (2017).

60 OuYang, F. P., Huang, B., Li, Z. Y., Xiao, J., Wang, H. Y. \& Xu, H. Chemical functionalization of graphene nanoribbons by carboxyl groups on Stone-Wales defects. J. Phys. Chem. C 112, 12003-12007 (2008).

61 Yang, X. Y., Zhang, X. Y., Liu, Z. F., Ma, Y. F., Huang, Y. \& Chen, Y. High-efficiency loading and controlled release of doxorubicin hydrochloride on graphene oxide. J. Phys. Chem. C 112, 17554-17558 (2008).

62 Xu, C. N., Wang, P., Zhang, J. P., Tian, H. Y., Park, K. \& Chen, X. S. Pulmonary codelivery of doxorubicin and siRNA by $\mathrm{pH}$-sensitive nanoparticles for therapy of metastatic lung cancer. Small 11, 4321-4333 (2015).

63 Zhao, Y. K., Tang, S. S., Guo, J. M., Alahdal, M., Cao, S. X., Yang, Z. C., Zhang, F. F., Shen, Y. M., Sun, M. J., Mo, R., Zong, L. \& Jin, L. Targeted delivery of doxorubicin by nano-loaded mesenchymal stem cells for lung melanoma metastases therapy. Sci. Rep.UK 7, 44758 (2017).

64 Oguejiofor, K., Galletta-Williams, H., Dovedi, S. J., Roberts, D. L., Stern, P. L. \& West, C. M. L. Distinct patterns of infiltrating CD8+ T cells in HPV+ and CD68 macrophages in HPV- oropharyngeal squamous cell carcinomas are associated with better clinical outcome but PD-L1 expression is not prognostic. Oncotarget 8, 14416-14427 (2017).

65 Wick, G., Grundtman, C., Mayerl, C., Wimpissinger, T. F., Feichtinger, J., Zelger, B., Sgonc, R. \& Wolfram, D. The immunology of fibrosis. Annu. Rev. Immunol. 31, 107-135 (2013).

66 Della Latta, V., Cecchettini, A., Del Ry, S. \& Morales, M. A. Bleomycin in the setting of lung fibrosis induction: from biological mechanisms to counteractions. Pharmacol. Res. 97, 122-130 (2015)

67 Yang, D. Z., Feng, L. Z., Dougherty, C. A., Luker, K. E., Chen, D. Q., Cauble, M. A., Holl, M. M. B., Luker, G. D., Ross, B. D., Liu, Z. \& Hong, H. In vivo targeting of metastatic breast cancer via tumor vasculature-specific nano-graphene oxide. Biomaterials 104, 361-371 (2016).

$68 \mathrm{Ma}$, J., Li, R. B, Qu, G. B., Liu, H. Y Yan, B, Xia, T. Liu, Y J \& Liu, S. J. Carbon nanotubes stimulate synovial inflammation by inducing systemic pro-inflammatory cytokines. Nanoscale 8, 18070-18086 (2016).

69 Wu, C. Y., Wang, C., Zheng, J., Luo, C., Li, Y. F., Guo, S. W. \& Zhang, J. Y. Vacuolization in cytoplasm and cell membrane permeability enhancement triggered by micrometer-sized graphene oxide. ACS Nano 9, 7913-7924 (2015).

70 Liu, Y., Wang, X. N., Wang, J., Nie, Y. G., Du, H., Dai, H., Wang, J. J., Wang, M. D., Chen, S. P., Hei, T. K., Deng, Z. X., Wu, L. J. \& Xu, A. Graphene oxide attenuates the cytotoxicity and mutagenicity of PCB 52 via activation of genuine autophagy. Environ. Sci. Technol. 50, 3154-3164 (2016).

71 Champion, J. A. \& Mitragotri, S. Role of target geometry in phagocytosis. Proc. Natl Acad. Sci. USA 103, 4930-4934 (2006).

72 Doshi, N. \& Mitragotri, S. Macrophages recognize size and shape of their targets. PLoS ONE 5, e10051 (2010).

73 Yang, K., Li, Y. J., Tan, X. F., Peng, R. \& Liu, Z. Behavior and toxicity of graphene and its functionalized derivatives in biological systems. Small 9, 1492-1503 (2013)

74 Baron, L., Gombault, A., Fanny, M., Villeret, B., Savigny, F., Guillou, N., Panek, C., Le Bert, M., Lagente, V., Rassendren, F., Riteau, N. \& Couillin, I The NLRP3 
inflammasome is activated by nanoparticles through ATP, ADP and adenosine. Cell Death Dis. 6, e1629 (2015).

75 Greenlee-Wacker, M. C. Clearance of apoptotic neutrophils and resolution of inflammation. Immunol. Rev. 273, 357-370 (2016).

76 Chang, S. C. \& Yang, W. V. Hyperglycemia, tumorigenesis, and chronic inflammation. Crit. Rev. Oncol. Hematol. 108, 146-153 (2016).

77 Mauer, J., Denson, J. L. \& Bruning, J. C. Versatile functions for IL-6 in metabolism and cancer. Trends Immunol. 36, 92-101 (2015).

78 Schmitt, N., Liu, Y., Bentebibel, S. E., Munagala, I., Bourdery, L., Venuprasad, K., Banchereau, J. \& Ueno, H. The cytokine TGF-beta co-opts signaling via STAT3-STAT4 to promote the differentiation of human TFH cells. Nat. Immunol. 15, 856-865 (2014).

79 Zhou, H. J., Zhao, K., Li, W., Yang, N., Liu, Y., Chen, C. Y. \& Wei, T. T. The interactions between pristine graphene and macrophages and the production of cytokines/chemokines via TLR- and NF-kappaB-related signaling pathways. Biomaterials 33, 6933-6942 (2012).

80 Kalantar-zadeh, K., Ou, J. Z., Daeneke, T., Strano, M. S., Pumera, M. \& Gras, S. L. Twodimensional transition metal dichalcogenides in biosystems. Adv. Funct. Mater. 25, 5086-5099 (2015).
81 Teo, W. Z., Chng, E. L. K., Sofer, Z. \& Pumera, M. Cytotoxicity of exfoliated transitionmetal dichalcogenides (MoS2, WS2, and WSe2) is lower than that of graphene and its analogues. Chem-Eur. J. 20, 9627-9632 (2014).

(c) (i) This work is licensed under a Creative Commons Attribution 4.0 International License. The images or other third party material in this article are included in the article's Creative Commons license, unless indicated otherwise in the credit line; if the material is not included under the Creative Commons license, users will need to obtain permission from the license holder to reproduce the material. To view a copy of this license, visit http:// creativecommons.org/licenses/by/4.0/

(C) The Author(s) 2018

Supplementary Information accompanies the paper on the NPG Asia Materials website (http://www.nature.com/am) 